\title{
Macroeconomic modelling under energy constraints: Global low carbon transition scenarios.
}

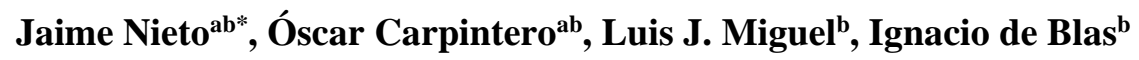

${ }^{a}$ Department of Applied Economics, Av. Valle Esgueva 6, University of Valladolid, Spain.

${ }^{\mathrm{b}}$ Research Group on Energy, Economy and System Dynamics, Paseo del Cauce, s/n, University of Valladolid.

\begin{abstract}
$\underline{\text { Abstract }}$
Integrated Assessment Models provide a framework to study sustainability transitions and their economic impacts. Models seldom consider energy constraints, taking supply availability for granted and thus suggesting a mere change in the energy mix from non-renewables to renewables. In order to address these limitations, a macro-economic module within a broader system dynamics model (MEDEAS) has been developed. The model has been run for the whole world from 1995 to 2050 under three different scenarios: Business as Usual (BAU), considering no further transition policies and keeping current trends; Green Growth (GG), undertaking the low-carbon transition according to the Paris Agreement set of policies and with high GDP growth standards; and Post-Growth (PG), testing the sustainability transition under a GDP nongrowth/degrowth approach. The results reveal the conflict between economic growth, climate policy and the sustainability of resources. Whereas a BAU approach would not even be an option to achieve climate goals, a GG view would not only face the downsizing of economic output, but neither would it be able to achieve the $2^{\circ} \mathrm{C}$ objective. The success of the PG approach in meeting emissions objectives suggests a redirection from economic growth policies to an industrial policy that incorporates efficiency and redistribution.
\end{abstract}

Keywords: Energy policy; Climate policy; Green growth; Post-growth; Integrated Assessment Models.

*Corresponding author.

E-mail address: jaime.nieto@eco.uva.es (Jaime Nieto). 


\section{Introduction}

Climate change is rapidly moving from being a potential, abstract threat to becoming a harmful reality. As a result, transitions towards sustainability, or low-carbon transitions, have emerged with a broadening body of literature (Markaard, Raven and Truffer, 2012). We define a low-carbon transition as the process aimed at a shift in the energy resources ant technologies that a society relies upon in order to achieve a state where zero or low carbon emissions are required to sustain the socioeconomic system (i.e. a low-carbon economy). Moreover, the international community is attempting to cope with climate change through different Conferences of Parties (COPs). The most relevant conference in recent years was COP21, where the Paris Agreement was signed. This agreement established as its main objective to "hold the increase in the global average temperature to well below $2^{\circ} \mathrm{C}$ above pre-industrial levels". Despite the Intergovernmental Panel on Climate Change (IPCC) stating that, in order to avoid surpassing the $2^{\circ} \mathrm{C}$ threshold, carbon emissions would have to be reduced between $41 \%$ and $72 \%$ by 2050 with respect to 2010 (IPCC, 2014), the Paris Agreement commitments deliver net increases, until at least (Rogelj et al., 2016; Raftery et al., 2017; Nieto, Carpintero and Miguel, 2018). Given the close relationship between emissions and energy consumption, any assessment of the economy's capacity to meet climate goals requires strong Energy-Economy-Environment (EEE) models, within the broader definition of Integrated Assessment Models (IAMs). Nevertheless, the concept of limits is rarely considered by either policy-makers or academic IAMs. Furthermore, ecological economics states that there are biophysical boundaries that the economy cannot exceed (Daly, 1968; Costanza, 1989, 1991; Farley and Daly, 2003). The analysis of Integrated Assessment Models (IAMs) is often split into two different approaches concerning the common features of how they characterize the economy, namely: optimization and simulation models (Scrieciu, Rezai and Mechler, 2013).

On the one hand, optimization models tend to use neoclassical production functions standard Constant Elasticity of Substitution (CES) functions- that assume perfect substitutability of productive factors, that markets clear and that a general equilibrium is reached. Optimization models assume well-behaved markets, coordinated via prices, and being the main driver of technological change and the focus of macroeconomic policies (e.g. carbon prices). Due to the usual convergence to markets equilibrium in these models, computable general equilibrium (CGE) models are the most representative amongst optimization model. Although they sometimes allow for multiple inferior equilibriums, their optimal growth (Sterman et al., 2012) path enforcing convergence towards full employment lead to superior equilibriums. However, despite 
their common use, these models have been widely criticised for not being grounded in the complex and dynamic reality.

On the other hand, simulation models rely on a different approach. The main contribution of simulation models is that they describe EEE relationships in a way that allow the propagation of disturbances into the system to be examined and the outcomes of the different policies to be evaluated. Simulation models do not optimize i.e. do not follow an optimum path, implying that markets do not necessarily clear, i.e. are in equilibrium. They conduct observation-based economic interactions modelling and provide more freedom to assess different phenomena (Scrieciu, Rezai and Mechler, 2013). Simulation models are often policy evaluation models and are not prescriptive as optimization ones are. Policies are not only market-driven, so institutions play an important role in policies definition. They pay special attention to income distribution and demand-led growth (as opposed as supply-driven in optimization models). Demand-led models are commonly sustained in Keynesian or post-Keynesian economics assuming disequilibrium, meaning non-clearing markets, demand-led growth although subject to certain supply constraints (Lavoie, 2014; Taylor, Rezai and Foley, 2016). As simulation fits better with dynamic modelling and disequilibrium economics, a number of models have been grounded on these approaches. Some examples are the non-equilibrium E3MG model (Pollit, 2014), ICAM (Dowlatabadi, 1998), GTEM (Kemfert, 2005), AIM (Kainuma, 2003; Morita et al., 2003; Masui et al., 2006) and IMAGE (Alcamo, Leemans and Kreileman, 1998; Bouwman, Kram and Goldewijk, 2006; Stehfest et al., 2014).

Nevertheless, a common weakness in both simulation and optimization models comes from the lack of integration between the economy and the biophysical system. In principle, the energy-economy nexus is not well developed, assuming a simple linear positive relationship between them. In a nutshell, exogenous economic growth boosts energy demand, which is in turn supplied by a changing energy mix. At best, this linear relationship is nuanced by energy efficiency gains, but its positive slope normally remains unchanged. Consequently, policy-makers are usually advised to focus on a mere technological transition towards a renewable energy mix, regardless of energy demand. Moreover, to our knowledge, most conventional models assume high degree of energy substitutability between energy technologies and resources, implicitly leaving energy availability unattended. This, together with the weak integration between the economy and the environment, lead these models to produce stable, gradual transitions pathways. . In addition, the economy is usually pictured as a monolithic energy-consuming machine, ignoring its complex sectoral structure and highly disaggregated decision-making. Although it is well known that energy resources are the key factor in low-carbon transitions, plans and 
international agreements do not usually take into consideration the aforementioned biophysical limits; something which could challenge their feasibility (McGlade and Ekins, 2015; Moriarty and Honnery, 2016; Spash, 2016; Nieto, Carpintero and Miguel, 2018). Therefore, in this paper, we argue that IAMs might be undervaluing the supply constraints of energy resources and the importance of the economic structure in low-carbon transitions.

To check this hypothesis, we have developed a model capable of overcoming these limitations. This model is the economy module of a broader system dynamics model named MEDEAS (Capellán-Pérez et al., 2017). The feedback-rich structure of system dynamics (SD) allows the model to consider energy limits. The best known contribution to simulation models was the pioneering World3 system dynamics (SD) model of Limits to Growth (Meadows et al.,, 1974; Meadows and Randers, 2013). Moreover, the economy module described in this article captures the economic structure through Input-Output analysis (IOA). Despite the existence of dynamic IO models, IOA has been criticised for assuming a fixed underlying technology, represented by the technical coefficients matrix. As the MEDEAS approach is grounded in SD and its scenario-based perspective, it can be adapted to a dynamic view. In addition, theoretical and policy-making implications for economic growth, energy availability and low-carbon transitions are also discussed. The article is structured as follows: section 2 sets up the theoretical framework of the methodology used; section 3 describes the functioning of the economic model developed; then, in section 4, the most relevant results are set out, according to the Business as usual, Green-growth and Post-growth scenarios; finally, section 5 summarises the main concluding remarks of the study.

\section{Theoretical framework: limits, economic structure and system dynamics}

The literature on sustainability transitions has been receiving increased interest from both scholars and policy makers consistent with the onset of the most visible impacts due to climate change (Markaard, Raven and Truffer, 2012). This body of literature, has been typically focused on sociotechnical change, innovation, agents' interrelations at different levels and increasingly on the metabolic structure of societies (Geels, 2002, 2011; Fischer-Kowalski and Haberl, 2007; Haberl et al., 2011). Sustainability transitions, as understood by the socio-metabolic approach, are characterised by the transformation of the current energy regime to a different one which does not surpass biophysical boundaries (Fischer-Kowalski, 2011). In other words, as stated by Raworth (2018), there is an environmental ceiling which the economy cannot breach, as well as 
a social floor. Between these boundaries, environmental and social sustainability should meet. These approaches connect with the tradition of ecological economics. Interaction between the economy and the environment, as understood by ecological economics, points out the subordination of the former to the limits imposed by the latter (Daly, 1968; Costanza, 1989, 1991; Farley and Daly, 2003). Concretely, as stated by Georgescu-Roegen(1971), according to the first and second principles of thermodynamics, the economy would be subject to irreversibility. This means that the entropic nature of the economic process degrades the amount and quality of energy resources and thus that economic growth, or even the steady-state, are limited by energy availability. Consequently, economic models should consider these limits to achieve a better understanding of the economic process (Georgescu-Roegen, 1975).

As stated before, system dynamics (SD) proves to be an adequate methodology for capturing these relationships, but it is also a relevant tool for economic analysis (Radzicki and Tauheed, 2009). Although it has typically been used by heterodox economists (Radzicki, 2009), it has recently even been extended to neoclassical models (Režný and Bureš, 2018). However, due to its features and functionalities, not assuming an a priori equilibrium, this technique has been much more attractive to the heterodox economists than to the neoclassical economists (Victor and Rosenbluth, 2007; Briens, 2015; Bernardo and D'Alessandro, 2016; Cordier et al., 2017). System dynamics was originated in control engineering and automation to determine a structure with different, interrelated input and output flows to fill or drain (respectively) different stocks. Two variables connected by a causal link, can change in the same direction (positive relationship) or in opposite directions (negative relationship). In a positive -or reinforcingfeedback loop, the growth of the first variable causes the growth of the second variable, but also the growth of the second variable causes the growth of the first variable. In a traditional predatorprey model with a lack of predators, a positive feedback loop emerges as the prey's population growth lead to an increase in births, in a self-reinforcing process. This would turn the system unstable unless a limiting factor is applied, creating a negative feedback loop, e.g. the introduction of more predators in the ecosystem. Therefore, the main advantage of SD is its capability to include feedbacks, which allows non-linear relationships between variables, better capturing realworld systems. Figure 1 shows a general simplification of the stock-flow feedback structure of SD. 


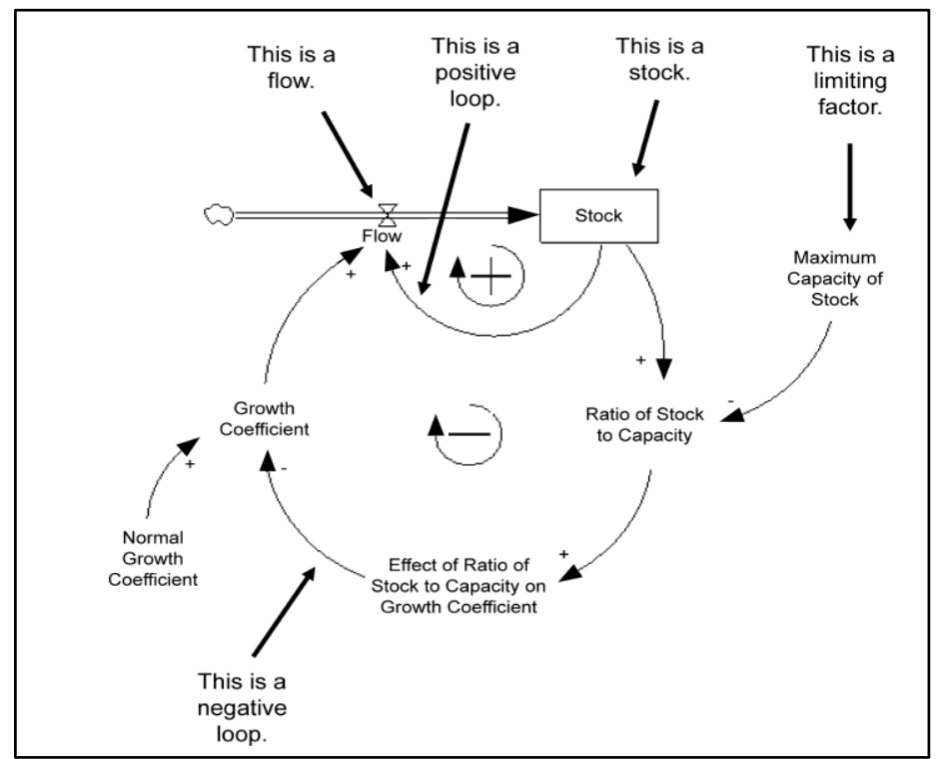

Figure 1. General overview of system dynamics structure based on stock, flow and feedback.

Source: Radzicki (2009)

The traditional (and widely spread among IAMs) energy-economy nexus, pictures a simple, one-way relationship whereby GDP growth leads to energy use mediated by energy intensity (Stern, 2011; Hall and Klitgaard, 2012; Foxon, 2017). Accordingly, the greater economic growth desired, the more energy is required to satisfy it (linear, positive relationship). However, if energy limits are to be considered, a better representation would be that of Figure 2 . GDP growth takes energy demand, which could be lowered by improving energy efficiency. In turn, primary energy reserves must be extracted and transformed into the final energy supply in order to meet this demand. As long as the energy needed to keep the GDP growing at a certain rate is satisfied by the energy supply, the relationship would still be positive. On the contrary, a restrained availability would force GDP growth down from its initial requirements. Therefore, a negative loop would have been established in the energy-economy nexus. In order to avoid such a situation, either an increase in primary energy production (extracting non-renewable energy resources (NRER) or installing new renewable energy source (RER) infrastructures) or a reduction in energy requirements (via efficiency gains or reducing GDP growth), or a combination of both, would be required. The first procedure alone would have to face NRER depletion and growing greenhouse gas emissions, as well as increasingly growth rates for the installation of RER infrastructures. The second procedure's main challenge would be to achieve net reductions in energy requirements, in such a way that GDP growth would not offset efficiency gains; otherwise, GDP would decline progressively, causing socioeconomic adversity as welfare relies on GDP. Thus, the economic process would be tied to energy constraints within a negative loop, leading to a non-linear relationship. Hence, Figure 2 shows the simplified theoretical SD structure 
of such an energy-economy feedback, whose concrete structure in our model is carefully explained in section 3. This forms the cornerstone of the MEDEAS-World model (Capellán-Pérez et al., 2017) and is, in particular, the economy module's main contribution.

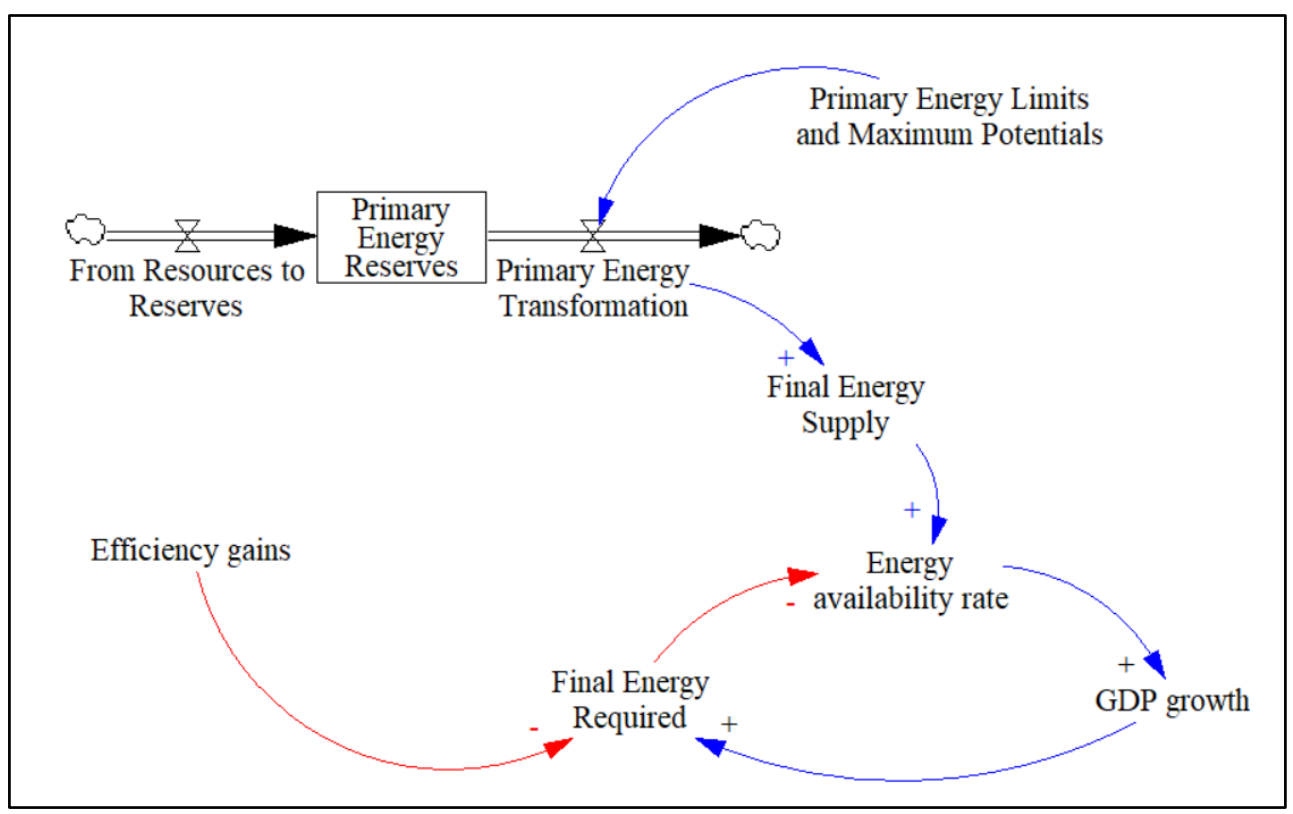

Figure 2. Negative feedback loop between GDP growth and energy availability.

Source: own elaboration.

The relevance of SD for capturing these kinds of relationship is highlighted by the remarkable success of Limits to Growth (Meadows, 1972), in estimating the fundamental tendencies of its key variables (Bardi, 2011; Meadows and Randers, 2013). Hence, the main advantage of system dynamics modelling consists of its capability to capture the complexity of systems, path-dependency across time and feedbacks (Uehara, Nagase and Wakeland, 2013; Capellán-Pérez, 2016). Nevertheless, correctly specifying the energy-economy nexus is of the utmost importance in order to improve the significance of the outcomes (Capellán-Pérez et al., 2015; Palmer, 2018). Despite this, there is still discussion on whether the sustainability transition would trigger a new era of 'green-growth' (Bowen and Hepburn, 2012; Kander and Stern, 2014; Csereklyei and Stern, 2015) or, conversely, would require a 'post-growth' approach involving degrowth or a steady-state economy (Daly, 1973; Kerschner, 2010; Jackson, 2011; Dietz and O’Neill, 2013; D’Alisa, Kallis and Federico, 2014; Lange, 2018).

Should the energy-economy linkage not be considered in the model, the economy would implicitly not be represented as subject to biophysical constraints. At best, the model's results could only be restrained to show a growing gap between energy demand and supply, suggesting instability for the economic system (Capellán-Pérez et al., 2015). Whereas mainstream economic 
theories argue that disequilibrium will be corrected via prices; quantities adjustment, put forward by the Keynesian tradition, is a more convenient approach given the biophysical nature of the MEDEAS model. Nevertheless, prices are still implicit in the model, embedded in the deflated monetary values (see section 3.1.3). Although scholars are increasingly coping with energy limits, only slight absolute or relative decreases in economic output are being reported (Kiuila, 2018; Režný and Bureš, 2018). Furthermore, these models and others might be overestimating the economy's capacity to keep growing under energy constraints. Arguably, their economic production supply approach, basically relying on capital and labour stock, might result in the partial irrelevance of energy constraints, as long as the growth in production factors offsets the effects of a scarcity of resources.

Recently, ecological macroeconomic models have gone one step further, introducing inequality, work patterns, economic structure and even a post-growth approach (Rezai and Stagl, 2016; Hardt and O'Neill, 2017). Supply limits are widely included, but often related to the effects of capital and labour supply on investment and employment, respectively. Environmental constraints generally appear as natural capital depletion (Bernardo and D'Alessandro, 2014; Fontana and Sawyer, 2016). Other research, such as that of Taylor, Rezai and Foley(2016), establishes that climate change would undermine investment and thus, economic growth. Nevertheless, it concludes that mitigation policies can stabilise climate with a cost not higher than $1 \%$ of global GDP. Finally, models using Input-Output analysis (IOA) allow the relevance of economic structure in EEE interactions to be captured (James, Jansen and Opschoor, 1978; De Haan, 2001). A combination of system dynamics and IOA provides significant results, as in Briens (2015), where an Input-Output-based system dynamics model is used to impose a degrowth scenario through different policies. IOA offers two main advantages against other methodologies. First, considering complementarity instead of perfect substitution better reflects the real performance of the productive process (Georgescu-Roegen, 1971; Stern, 1997; Farley and Daly, 2003; D'Alessandro, Luzzati and Morroni, 2010). Second, capturing both direct and indirect effects of a variation in final demand on sectoral production delivers more accurate monetary outcomes, as well as the energy carriers of production (Leontief, 1970; Miller and Blair, 2009). Despite the undeniable relevance of economic structure, models often forecast huge economic and technological transformations, maintaining it unaltered. For instance, we can expect different results from the current economic structure than those obtained after a transition where fossil fuel refineries are no longer as important as they are nowadays. For this reason, technical coefficients vary along time according to scenarios (see Appendix B). 


\section{Modelling a feasible world economy. Methodology}

MEDEAS-World is a global model in which the world is considered as one region within the IO framework, i.e. trade flows are disregarded. This global region is the result of the aggregation of 39 countries and a Rest of the World region (see section 3.1.3.). It is a simulation model, based on system dynamics (SD), built on different modules that are shown in Figure 3 (Capellán-Pérez et al., 2017). The validation of the models has been carried out following several of the usual validation procedures of models in system dynamics (Barlas, 1996; Sterman, 2000). Following them, "structure validity", "extreme-condition", "behaviour-sensitivity", "boundaryadequacy", "dimensional consistency" and "behaviour-reproduction" tests have been carried out. Sensitivity analysis has also been applied to the variables subject to more uncertainty of the model. The historical data, although the available series are short, has been used for a first validation. Subsequently, the models have been subjected to a robustness test. Sensitivity analysis have been made and results compared with other models.

Considering that the purpose of this paper is to evaluate the economy module, only relevant connections with it are described. Concisely, economic output requires a certain level of energy demand and this is compared with energy supply availability. So, the energy and the economy module are two-way integrated through energy demand and energy availability. Final energy demand is the main result of the combination of the economy and energy module's operations and the most relevant link with the rest of the model. The economy module's outputs are: energy demand, direct and indirect (the land use required) $\mathrm{CO}_{2}$ emissions, materials demand (through the demand of new energy infrastructures) and other social and environmental impacts. The main feedbacks to the economy module from the rest of the model, apart from exogenous variations described later, are delivered by the climate change impacts (CC damage function), (EROEI) and the energy supply availability. Figure 6 shows the simplified influences diagram of the economy module, illustrating the main relationship between the variables. For the sake of simplicity, in this paper, only energy-related feedbacks are activated. Thus, there is no influence 
of the climate change damage function in our results. The MEDEAS-World model considers 35 different industries (see Appendix A), as the main source for IOA is the World Input-Output Database (WIOD) (Dietzenbacher et al., 2013). The WIOD was selected because of its public data, its environmental accounts (Genty, 2012), especially regarding energy, and its socioeconomic accounts (Timmer et al., 2015). Despite the significant sectoral disaggregation, energyrelated sectors do not differentiate between energy types. For instance, sector 2 (Quarry and Minery) include indistinctly non-energy and energy-related materials; sector 8 (Coke oven, Refined petroleum and Nuclear fuel) as well as sector 17 (Electricity, Gas and Water supply) include several final energy use types. All sectors have been taken as energy-demanding including the energy-related ones and therefore, energy supply is estimated in the energy module according to the final energy requirements of all sectors. All the same can be applied to materials.

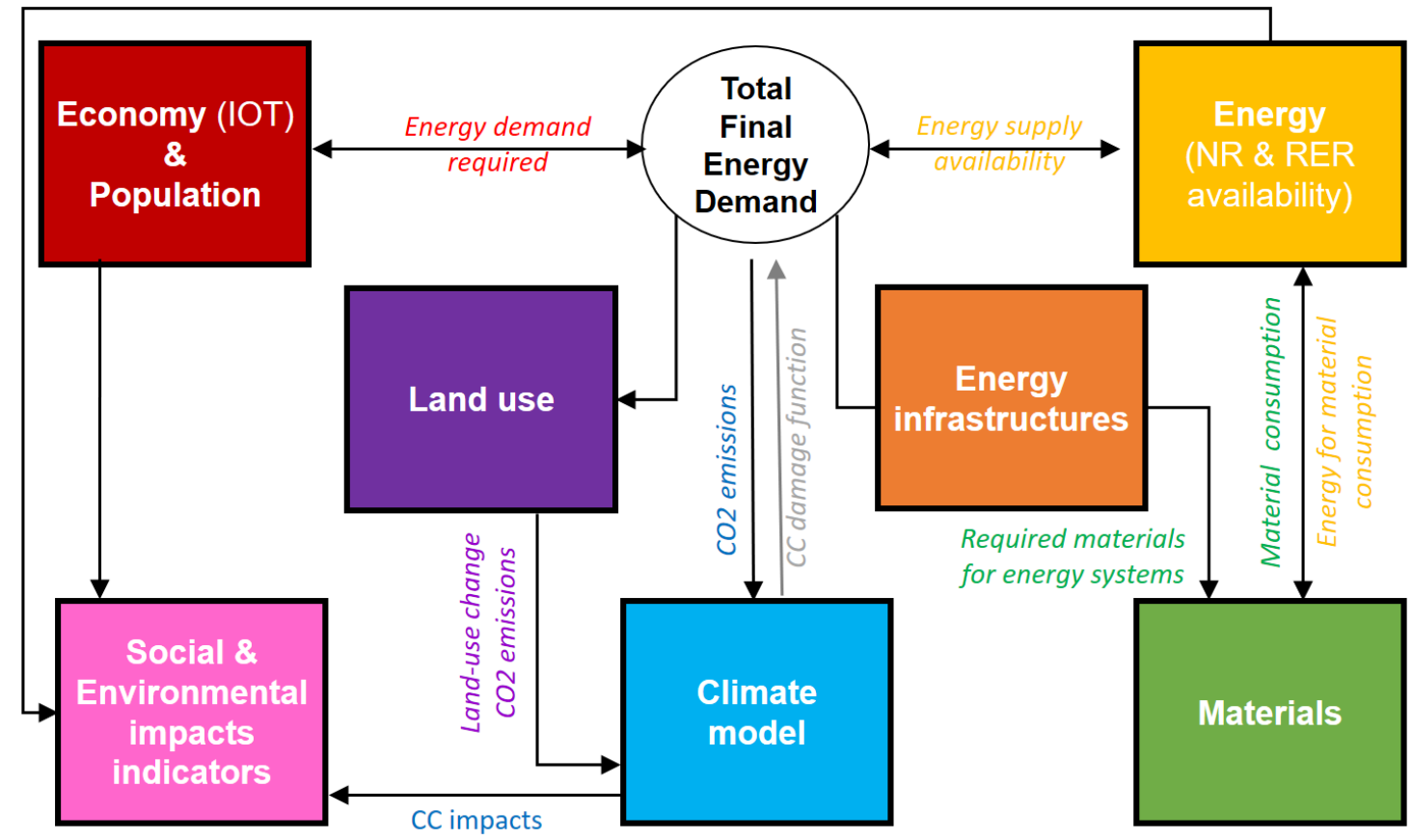

Figure 3- MEDEAS-World model schematic overview. Source: (Capellán-Pérez et al., 2017)

Before going into the economy module's particulars, it is worth giving an overall view of how the whole MEDEAS world model functions. The different module functionalities are the following (see in brackets the corresponding section in Capellán-Perez et al. (2017) where further information can be found): 
1. Economy (IOT) \& Population (Economy module): through hybrid (i.e. combining monetary and physical units, see sections 3.1.3 and 3.1.4) Input-Output Analysis, the final energy demand by industries and the final end-use energy carriers are estimated. Subsequently, it will be referred as final energy demand and supply when not mentioning different end-use energy carriers [section 2.2 in Capellán-Perez et al. (2017)] 2. $\quad$ Energy (NR \& RER availability) (Energy module): this includes the renewable (RER) and non-renewable energy (NRER) resource potentials and availability, taking into account biophysical and temporal constraints. In total, 5 final end-use energy carriers are considered (electricity, heat, solids, gases and liquids) and a diversity of energy technologies are modelled. The energy module provides the net final energy supply which, in turn, constrains the final energy use by the economy. This energy-economy feedback is not often taken into consideration in the literature, which could lead models to unfeasible results. [section 2.3 in Capellán-Perez et al. (2017)]

3. Energy infrastructures module: this estimates the infrastructure deployment of power plants to generate electricity and heat. [section 2.3 in Capellán-Pérez et al. (2017)] 4. Materials module: materials required by the economy, and especially for the construction of energy infrastructures, are tracked by MEDEAS. [section 2.4 in CapellánPérez et al. (2017)]

5. Climate module: this projects the GHG emissions of the system, which could also be fed back through a damage function. However, as mentioned above, this feedback has been deactivated for the purpose of this work and is shown in grey in Figure 3. [section 2.5 in Capellán-Pérez et al. (2017)]

6. Land use module: land-use requirements of the RER are accounted in the landuse module. [section 2.6 in Capellán-Pérez et al. (2017)]

7. Social and environmental impacts indicators: this module collects the main outcomes regarding impacts in these two areas. [section 2.7 in Capellán-Pérez et al. (2017)]

\subsection{The economy module}

The MEDEAS-World economy module's general structure could be summarised in a sequential way as shown in Figure 4; whereas a more detailed, simplified influence diagram can be seen in Figure 6. Likewise, Appendix D shows the system dynamics structure of the model in several views, as depicted in the software employed. The economy module is sectorally disaggregated by 35 industries (see Appendix A), is demand-driven and subject to energy 
feedbacks. Basically, exogenous final demand growth is imposed by scenarios regarding population and GDP per capita growth. Then, along with income share scenarios, the adequate inputs are delivered to feed the sectoral final demand function, which distributes this growth amongst industries. Once the variation of the sectoral final demand is known, Input-Output Analysis (IOA) obtains the output required by each industry to satisfy it. As energy is needed to produce economic output, energy coefficients (namely, sectoral final energy intensities) permit the model to obtain the final energy required (by energy source) to produce the sectoral output. Both final energy intensities and economic structure, represented by the A matrix (see section 3.1.3), evolve during the simulation period according to their historical trends and scenario assumptions. Depending on the final energy of each type needed for the economy to grow at a predetermined rate, the energy module (influenced by the others) computes ways to deliver. Primary energy must be extracted and transformed, new infrastructures might have to be deployed, and materials must be extracted and processed to fulfil this commitment. Therefore, taking into account NRER depletion curves, EROEI, RER potential and growing installed capacity, the energy module delivers the final energy availability. After that, final energy demand and final energy supply are compared, providing the model with the feasible production and, in turn, feasible final demand, by inversely applying IOA. Therefore, although energy and economic demand begin the simulation as being completely exogenous, they become endogenous as soon as energy scarcity appears.

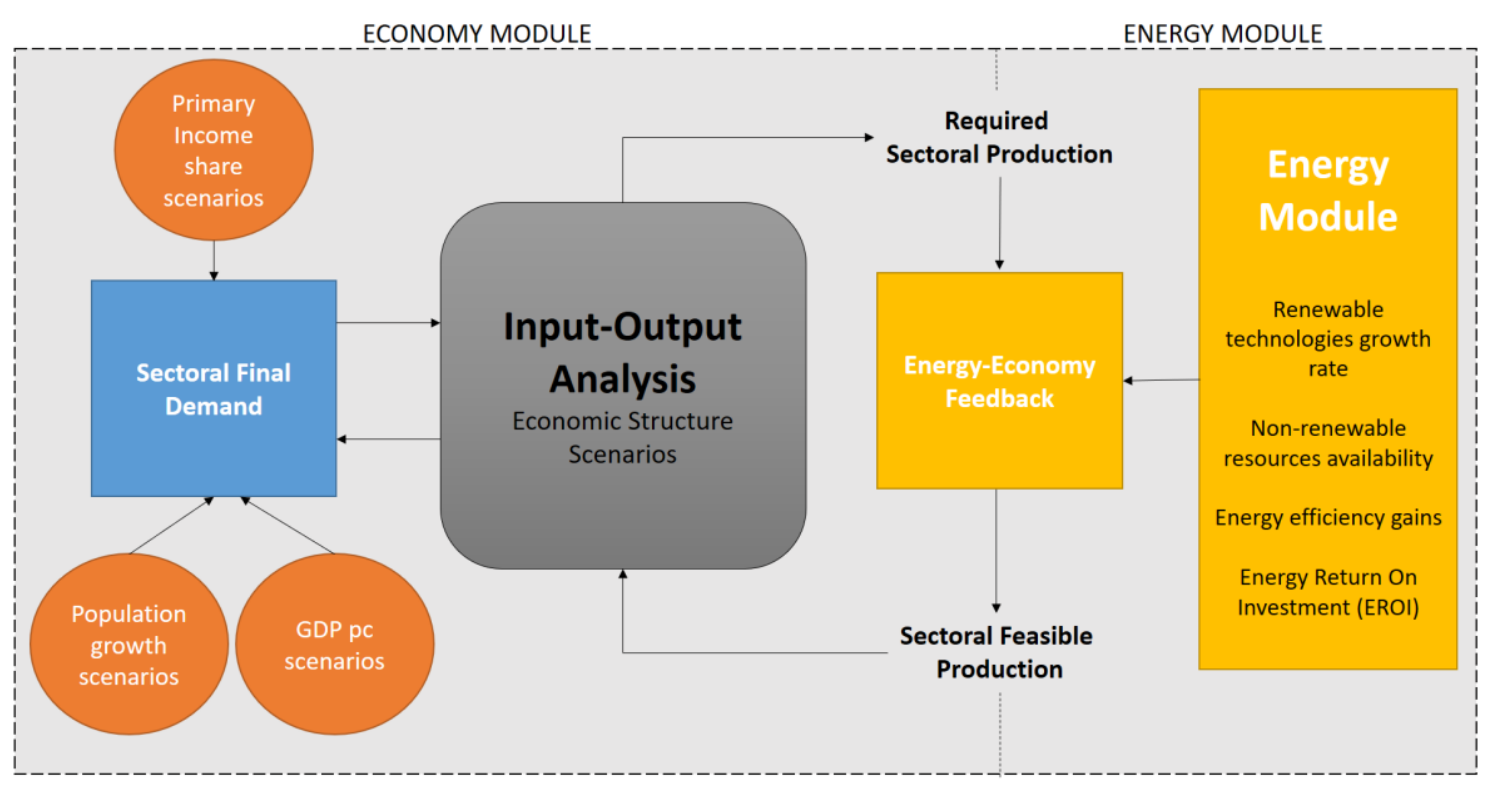

Figure 4. Economy module structure and main energy inputs. Source: own elaboration. 


\subsubsection{Primary Income}

As mentioned before, the economy module is demand-driven. An exogenous final demand variation via Gross Domestic Product per capita (GDPpc) is forced into the system regarding past trends and scenario storylines. Given that population growth is also determined exogenously, total expected GDP growth is easily calculated by multiplying GDPpc and population. Labour and capital compensation (wages and gross profits respectively), i.e. primary income, is estimated by the model because it is the main input to final demand functions -in households' consumption and gross fixed capital formation-, as described in section 3.1.2. For this reason, primary income share (the proportion represented by each primary income category over GDP) scenarios have been established according to their characteristics (see section 4). Then, labour and capital compensation is obtained by multiplying GDP by these exogenous income shares. Let $l a b$ and $c a p$ be labour and capital compensation respectively. Then, $\alpha_{\mathrm{lab}}=\frac{\mathrm{lab}}{\mathrm{GDP}}$ and $\alpha_{\text {cap }}=\frac{\text { cap }}{\text { GDP }}$ stand for each primary income share . They gradually evolve from their initial observed value until they reach each scenario target value. Therefore, by multiplying GDP by $\alpha_{\text {lab }}$ and $\alpha_{\text {cap }}$, we obtain the primary income lab and cap. Hereafter, primary income distribution -that will be noted indistinctly as income distribution- operates as an input for sectoral final demand functions.

\subsubsection{Final demand}

After the previously explained economy-wide variation in final demand is estimated, final demand is distributed among industries. For this purpose, a sectoral final demand function has been estimated by institutional sectors running panel data regressions, taking income as the main explanatory variable. All regressions are corrected for autocorrelation, heterokedasticity and contemporary correlation depending on the case, while Eq. 1 defines the components of the sectoral final demand function:

$$
\mathbf{f d}=\mathbf{c}+\text { gfcf }+ \text { ge }+ \text { invent }
$$

Where fd is the $35 \times 1$ vector of final demand formed by its vector components such as $\mathrm{c}$, thehouseholds and non-profit organisations serving household consumption, gf cf is gross fixed capital formation, ge is government expenditure and invent is changes in inventories and valuables. Following the conditions imposed by the database used, gfcf measures the investments made by each institutional sector in durable products produced by industry ' $i$ '. For this reason, considering that almost half of investments are concentrated in the construction sector and the 
significant weight of households in construction investment, gfcf_18 (i.e. gross fixed capital formation in the construction sector, number 18 in Appendix A) has been modelled separately due to its particularities (a high proportion of households' investment). Likewise, ge is relatively autonomous or, at best, inversely linked to the economic cycle. Even in this case, nothing can ensure that ge will perform in this way, as it basically depends on policy choices. Because of this, ge by industries is exogenously considered the proportion of each industry's final demand -e.g. $66 \%$ in Education or $4.5 \%$ in Inland transport- of the last available historical observation. The same approach has been followed to include invent because of its residual weight in total final demand. Eq. 2-Eq. 4 collect the main structure of each sectoral final demand disregarding vector notation (see Details in Appendix A).

$$
\begin{aligned}
& \ln (c)=\beta_{0}+\beta_{1 i} \operatorname{Sec}_{i}+\beta_{2} \ln (L a b) \quad \text { i } \in 1 \ldots 35 \quad \text { Eq. } 2 \\
& \ln (g f c f)=\beta_{0}+\beta_{1 i} \operatorname{Sec}_{i}+\beta_{2} \ln (\text { Cap }) \quad \mathrm{i} \in 1 \ldots 17 \cap 19 \ldots 35 \quad \text { Eq. } 3 \\
& \ln \left(g f c f_{-} 18\right)=\beta_{0}+\beta_{1} \ln (L a b)+\beta_{2} \ln (C a p) . \quad \text { Eq. } 4
\end{aligned}
$$

where $\beta_{0}$ is the intercept of each function, $\beta_{1 i}$ is the sectoral intercept that captures the structural effects of sectoral distribution in panel data regressions, $S e c_{i}$ is a dichotomous variable with value 1 when forecasting the actual sector and 0 otherwise. Lab stands for labour compensation (wages) and Cap for capital compensation (gross profits), while $\beta_{2}$ stands for the coefficients multiplying the explanatory variables. Subscript i indicates the different industries. Although the literature usually takes interest rates as an explanatory variable, there are difficulties to estimate a global interest rate, which leads us not to include it in our world model. The literature also suggests that the effects of real interest rates differ radically between regions (Hein and Ochsen, 2003); are not clear (Lavoie, 1995, 2014); or are even non-significant (Stockhammer, Onaran and Ederer, 2009). All the institutional sectors' final demand rely on income: con wages, $g f f$ on gross profits and $g f c f_{\_} 18$ on both primary income components, given the abovementioned particularities. Therefore, sectoral final demand is a function of economic structure and income.

\subsubsection{Input-Output Analysis}

Once the first economy-wide variation in final demand is distributed among the 35 industries, Input-Output Analysis allows the production required to satisfy each industry's demand (Miller and Blair, 2009) to be calculated. The WIOD database includes 41countries (including OECD countries, other major economies and a Rest of the World region) containing 
the whole world economy. Nonetheless, because MEDEAS takes the world as one economy with no international trade, all countries have been collapsed into just one. Furthermore, original IOT series in previous year prices have been translated into a World IOT in chained, linked volumes with a mobile base year.

Multirregional IOT

\begin{tabular}{|c|c|c|c|c|c|c|}
\hline \multicolumn{3}{|c|}{ Intermediate Demand } & \multicolumn{3}{|c|}{ Final Demand } & \\
\hline$z_{1,1}$ & $z_{1}, \ldots$ & $z_{1, n}$ & $f d_{1,1}$ & $f d_{1, \ldots}$ & $f d_{1, n}$ & $x_{1}$ \\
\hline$z_{\ldots, 1}$ & $Z_{\ldots, \ldots}$ & $Z_{\ldots, n}$ & $f d_{\ldots, 1}$ & $f d_{\ldots, .}$ & $f d_{\ldots, n}$ & $x_{\ldots}$ \\
\hline$z_{n, 1}$ & $z_{n, \ldots}$ & $z_{n, n}$ & $f d_{n, 1}$ & $f d_{n, \ldots}$ & $f d_{i, n}$ & $x_{n}$ \\
\hline$G V A_{1}$ & $G V A_{\ldots}$ & $G V A_{n}$ & & & & \\
\hline$x_{1}$ & $x_{.}$ & $x_{n}$ & & & & \\
\hline
\end{tabular}

One Region IOT - World IOT

\begin{tabular}{|c|c|c|}
\hline $\begin{array}{l}\text { Intermediate } \\
\text { Demand }\end{array}$ & $\begin{array}{c}\text { Final } \\
\text { Demand }\end{array}$ & \\
\hline$z_{i, j}$ & $f d_{i}$ & $x_{i}$ \\
\hline$G V A_{j}$ & & \\
\hline$x_{j}$ & & \\
\hline
\end{tabular}

Figure 5. From interregional Input-Output tables (IOT) to a World IOT.

Regional disaggregation. $z_{1, n}$ : intermediate consumption from region 1 to region $\mathrm{n} ; f d_{1, n}$ : final demand of products and services from region 1 made by region $\mathrm{n} ; x_{n}$ : production in region $\mathrm{n} ; G V A_{n}$ : gross value added in region $\mathrm{n}$. Sectoral disaggregation: represented in the One Region IOT. $z_{i, j}$ refers the sales from sector ' $\mathrm{i}$ ' (rows) purchased by sector ' $\mathrm{j}$ ' (columns). Gross Value Added is measured by columns ' $\mathrm{j}$ ' and $x_{i}=x_{j}$ representing that all the production responds to demand requirements (demand not satisfied is measured as Changes in inventories).

Source: own elaboration

Figure 5 indicates that intermediate consumption are the trade flows between sectors that simultaneously behave as sellers (subscript ' $\mathrm{i}$ ' in rows) and purchasers (subscript ' $\mathrm{j}$ ' in columns) $\left(z_{i j}\right)$. This delivers a squared matrix with 35 different industries (see Appendix A). Total Gross Value Added (GVA) equals total Final Demand (fd), and therefore total GDP. Production can be measured demand-side as the sales of sector ' $i$ ' plus the final demand of products and services from sector ' $i$ ' or supply-side as the sum of total intermediate products purchases of sector ' $\mathrm{j}$ ' from the rest of sectors ' $\mathrm{i}$ ' plus the GVA ( $l a b$ and cap) generated in this sector ' $\mathrm{j}$ '. This supplyside view is crucial to understand the structural relationships between industries, i.e., the amount of inputs from each industry needed by others to produce 1 unit of product. Thus, technical coefficients measure the fixed complementary relationship between inputs and outputs according to Eq. 5: 
$a_{i j}=\frac{z_{i j}}{x_{j}} \quad \mathrm{i}, \mathrm{j} \in 1 \ldots 35$

Eq. 5

where $a_{i j}$ is the technical coefficient of sector $\mathrm{i}$ over sector $\mathrm{j}$. Let us denote $\mathbf{A}$ as the squared technical coefficients matrix including all $a_{i j}$ and $\mathbf{Z}$ the squared matrix of intermediate consumption including all $z_{i j}$. Finally $\hat{\mathbf{x}}$ is the diagonal matrix of sectoral production. Hence, in matrix notation, $\mathbf{A}=\left[a_{i j}\right]=\mathbf{Z} \hat{\mathbf{x}}^{-1}$ and thus $\mathbf{Z}=\mathbf{A} \hat{\mathbf{x}}$. As said before, from a demand point of view, production is the sum of intermediate consumption and final demand. In matrix notation $\mathrm{x}=Z+$ $f d$ being ' $\mathrm{x}$ ' the column vector of sectoral production and ' $\mathrm{fd}$ ' the final demand vector, therefore.

$$
\begin{array}{ll}
\mathbf{x}=\mathbf{A} \cdot \mathbf{x}+\mathbf{f d} & \text { Eq. } 6 \\
\mathbf{x}==(\mathbf{I}-\mathbf{A})^{-1} \cdot \mathbf{f d} & \text { Eq. } 7 \\
\mathbf{X}=\mathbf{L} \cdot \mathbf{f d} & \text { Eq. } 8
\end{array}
$$

where $(\mathbf{I}-\mathbf{A})^{-1}=\mathbf{L}=\left[l_{\mathrm{ij}}\right]$ is the so-called Leontief inverse, reflecting the elasticity of production (x) to changes in final demand (fd). In other words, it measures how production reacts to satisfy a variation in final demand, so sectoral production is obtained through IOA in MEDEAS. Considering that static technical coefficients would not be a reasonable assumption for such a long simulation period encompassing structural change, the A Matrix evolves according to tendencies and scenarios. The evolution of the A matrix is set to begin by 2020 and to finish as soon as either the consistency condition is met $^{1}$, or the simulation period reaches 2050. Table 2 shows each scenario assumption and Appendix B shows the different target matrices towards which the original A matrix evolves.

\subsubsection{Energy-Economy Feedback}

Most EEE models take economic growth as given within a certain exogenous growth rate, which also drives energy demand. Therefore, economic and energy demand show a positive slope, occasionally nuanced by efficiency gains in the case of energy (a kind of relative decoupling between them). In addition, energy demand is always met by energy supply and the only problem to be solved is the energy mix which defines the said supply. In the MEDEAS world model, the economy receives a feedback from the energy system so, if the energy supply is not enough to meet the demand, economic output must be reduced. It is important to recall that, although energy

${ }^{1}$ According to Input-Output Table accounting balances, the column sum of technical coefficients $(\mu)$ must be lower than 1 , where $(1-\mu)$ is the share of value added in sectoral production. Given that certain sectoral structural coherence must be maintained, each sector's technical coefficients stop evolving as soon as $(1-\mu)$ becomes one third of its original value. 
stock (reserves for NRER and energy potentials for RER) naturally determines its feasible amount, it is the energy supply flow and not the stock which has to match the final energy demand flow for each period. This means that the extraction, processing and distribution for NRER and infrastructure deployment, as well as the generation and distribution for RER, are the activities that deliver the final energy supply flow. This means that energy scarcity can surge, even if energy reserves and potentials are still available to transform into final energy (see Figure 2). Because this flow is determined by the energy infrastructures deployed in past periods, the system's capability to fully satisfy the economy's demand is path-dependent.

In the previous section, how the production required to satisfy demand by sectors was calculated. After that the hybrid Input-Output analysis with energy intensities (e) as the energy coefficients is conducted. Being $\widehat{\mathbf{f e d}}^{k j}=\left[\mathbf{f e d}_{\mathbf{k j}}\right]$ the $35 \times 35$ diagonal matrix of final energy demand by 5 final end-use energy carriers ' $k$ ' and 35 sectors ' $\mathrm{j}$ ', the $175 \times 175$ diagonal matrix of total final energy demand ( $\widehat{\text { fed }})$ is

$$
\widehat{\mathbf{f e d}}=\left[\begin{array}{ccc}
\widehat{\mathbf{f e d}}^{11} & \mathbf{0} & \mathbf{0} \\
\mathbf{0} & \ddots & \mathbf{0} \\
\mathbf{0} & \mathbf{0} & \text { fed }^{\mathrm{kj}}
\end{array}\right] ; \mathrm{k} \in 1, \ldots, 5 ; \mathrm{j} \in 1, \ldots, 35
$$

The same structure could be applied to energy intensities, so we have the $\mathbf{e}^{\mathbf{k j}}$ diagonal matrix of diagonal matrices of each sectoral final end-use energy carrier. Then, $\hat{\mathbf{x}}^{-1}$ is the diagonal matrix of sectoral production, according to Eqs. 9-10:

$$
\begin{aligned}
& \widehat{\mathbf{e}}^{\mathbf{k j}}=\widehat{\mathbf{f e d}}^{\mathbf{k j}} \bullet \widehat{\mathbf{x}}^{-1}=\left(\begin{array}{ccc}
\frac{f e d_{11}}{x_{1}} & 0 & 0 \\
0 & \ddots & 0 \\
0 & 0 & \frac{f e d_{k j}}{x_{j}}
\end{array}\right)=\left(\begin{array}{ccc}
e_{11} & 0 & 0 \\
0 & \ddots & 0 \\
0 & 0 & e_{k j}
\end{array}\right) \quad \text { Eq.9 }
\end{aligned}
$$

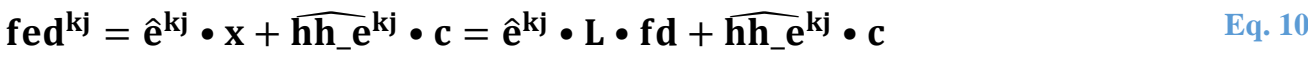

Thus, the module uses an identity (Eq. 9) to estimate the final energy demand by sector $\mathrm{j}$ and source $\mathrm{k}\left(\mathbf{f e d}^{\mathbf{k j}}\right)$. The final energy demand would be the result (Eq.10) of multiplying sectoral energy intensities $\left(\hat{\mathbf{e}}^{\mathbf{k j}}\right)$ by production $(\mathbf{x}=\mathbf{L} \bullet \mathbf{f d})$ plus the $35 \times 35$ households energy intensities by resource and sector diagonal matrix $\left(\widehat{\mathbf{h h}}^{\mathbf{k j}} \mathbf{k}^{\mathbf{k}}\right)$ multiplied by households' consumption (c). Appendix $\mathrm{C}$ describes how to estimate separately the direct and indirect effects of the final energy demand, which do not correspond to the two different components in Eq.10. Then, the model checks whether the total energy demand by resource $\left(\mathbf{t f e d}=\left[t_{f e d}\right]=\sum_{\mathbf{j}=1}^{35} f e d_{k j}\right)$ is higher or lower than the final energy supply by end-use carrier $\left(\mathbf{t f e s}=\left[t_{f e} s_{k}\right]\right)$. Consequently, Eq. 11 shows how feasible energy demand $\left(\mathbf{f}_{-} \mathbf{f e d}^{\mathbf{k j}}\right)$ is calculated: 


$$
\mathbf{f}_{-} \mathbf{f e d}^{\mathbf{k j}}=\mathbf{f e d}^{\mathbf{k j}} \bullet \varepsilon ; \varepsilon=\operatorname{Min}\left(1, \frac{\mathrm{tfes}}{\mathbf{t f e d}}\right) . \quad 0<\varepsilon>1
$$

with $\varepsilon$ as a shortage coefficient valued as being 1 when tfes $\geq$ tfed, and thus no energy constraints, and the quotient between them otherwise. As there is no assumption of perfect substitutability in either economic or energy inputs, the type of energy which is lacking in a higher proportion (i.e., the minimum quotient in Eq.11) determines the shortage coefficient. Moreover, for the sake of simplicity, it has been considered that economic output decreases proportionally amongst industries in the case that shortages appear. Thus, feasible sectoral energy demand imposes a new sectoral feasible output which, by taking it instead of the required output, and rearranging Eq. 10, we have:

$$
\mathbf{f}_{-} \mathbf{x}=\mathbf{e}^{-1} \cdot \mathbf{f}_{-} \mathbf{f} \mathbf{e d}^{\mathrm{kj}}
$$

Eq. 12

Finally, introducing Eq. 11 into Eq. 12:

$$
\mathbf{f}_{-} \mathbf{x}=\mathbf{e}^{-1} \cdot \mathbf{f e d}^{\mathbf{k j}} \cdot \operatorname{Min}\left(1, \frac{\mathbf{t f e s}}{\mathbf{t f e d}}\right)
$$

Therefore, economic output is a function of energy intensity (negative effect), energy demand and energy supply when $\mathbf{t f e s}<\mathbf{t f e d}$. Moreover, considering that energy demand stands for Eq. 10, the economic output would also, indirectly, be a function of economic structure and final demand. Lastly, conducting an inverse IOA, final demand satisfied by feasible output is obtained-solving Eq. 7 for $\mathbf{f d}$ instead of $\mathbf{x}$ - delivering the feasible final demand.

Energy constraints do not have to be seen as a literal shortage, such as, for instance, gasoline running out in petrol stations. Conversely, as long as it takes energy to produce economic output, it should be seen as limiting the economy's maximum potential. Considering this outcome, as total final demand equals total GDP in the world economy, income in the subsequent years is obtained by multiplying this figure by labour and capital shares. Hence, income becomes endogenous as soon as energy scarcity appears. This approach raises the question of economic growth feasibility under biophysical (energy) constraints. Regarding the importance of energy supply to determine economic output, a brief overview of the energy module is provided below. In order to evaluate how sensitive the results are to this energy-economy feedback, it can be deactivated by disregarding geological limits. 


\subsection{Energy Module}

Energy availability is the main output of the Energy module; it is the core, most developed and complex module in MEDEAS. In order to fully understand its internal rationale and concrete mechanisms, it would be advisable to see the model's technical report (Capellán-Pérez et al., 2017), where it is thoroughly described in section 2.3. Nonetheless, for the sake of simplicity, the essentials for understanding its relationships with the Economy module are briefly noted. Basically, the Economy module demands a certain volume of each final end-use energy carrier from the energy system, which in turn delivers the energy available to satisfy it.

The main processes which take place in the Energy module refer to the installed capacity of renewable energy, the availability of non-renewable energy resources, the energy efficiency gains and the EROEI. Basically, RER installed capacity and NRE availability are estimated according to different scenarios based on literature, and regarding different technologies and primary resources, respectively. The literature used for this purpose is shown in Table 2 in section 4. The maximum extraction curves impose a limit to yearly NRER extraction, which endogenously evolve in a path-dependent way since they are bounded to the extraction in precedent years and therefore, to final energy demand. Moreover, given the high uncertainty involving the extraction curves, the 'Middle' and 'Best Guess' options have been selected in order to avoid extreme, unrealistic outcomes. In fact, the results shown in this article compare the situation regarding and disregarding energy limits. More information and a thorough literature review on depletion curves can be found in section 2.3.3 in Capellán-Pérez et al. (2017).

The selection of renewable energies starts from the historical evolution data and establishes the maximum values of annual growth. These values can be modified by the user of the model. Demand drives the development of new infrastructures (power plants). The distribution of the power plants among the different options is currently chosen based on the EROEI, and taking into account other restrictions. The choice of EROEI as a criterion is based on the need to optimize the total consumption of energy in a scenario of limited energy resources. Section 2.4.5. in Capellán-Pérez et al. (2017) provides more insights on this. Also, de Castro et al. (2019) discusses further on that, as well as on the role of EROEI in MEDEAS model.

Moreover, given the inertia and rigidities in the productive processes highly dependent on natural resources, adjustments are typically produced with quantity changes (instead of prices, i.e. costs), as post-Keynesian approaches have highlighted (Lavoie, 2014). Sectoral final energy intensities have been estimated for each scenario as well, with particular regard to the transport sectors. Finally, as long as the system transits to a different energy mix, the higher (lesser) EROEI 
provided by the actual technologies and resources, the lesser (higher) installed capacity will be required to satisfy the same amount of energy demand (i.e., if EROEI declines, an additional 1\% of energy demand would take more than an additional $1 \%$ of energy capacity installed).

\section{Low-carbon economies coping with the limits. Results.}

The transition towards low-carbon economies needs the implementation of policies, time to fully deploy them, and an economic system to support them. The combination of these elements shapes different scenarios for the most likely future landscape. The most relevant results from scenarios, in terms of climate and economic policy, can be represented by emissions and GDP growth (see section 4.1), as described below. Furthermore, economic structural change is evaluated in section 4.2. In this article, we have considered three different scenarios, following specific storylines and the extended simulation period until 2050. The Business as Usual (BAU) scenario basically provides the model with inputs based on current trends and no further policies to meet climate goals.

Conversely, the Green Growth (GG) scenario storyline states the deployment of a technology-based set of policies aimed at achieving the climate goals (i.e., the $2^{\circ} \mathrm{C}$ Paris Agreement objective) boosted by economic growth (Bowen and Hepburn, 2012; Kander and Stern, 2014; Csereklyei and Stern, 2015). According to the key assumptions in the different 'scenarios families' given by van Vuuren et al. (2012), this scenario would be consistent with the SSP1 narrative. This implies relatively low population growth rates, high economic expectation (Expected GDPpc growth), high increase in energy efficiency and transition policies towards a renewable energy mix. Higher GDPpc growth rates are grounded on high development expectations for the Low and Medium Income countries and medium expectations for the High Income Countries. Since the Paris Agreement can be described as following a green growth approach (Nieto et al., 2018; Spash, 2016), its policies could be considered the foundation of this scenario. These policies can be summarised as a common objective to electrify the economy, being complemented by a general switch to RER in the electricity energy mix, although including nuclear energy. In addition, policies are aimed at fostering bioenergy and energy efficiency gains, especially in the transport sector. Finally, the general spirit of the policies aims to achieve all these goals with a so-called 'inclusive economic growth'. 


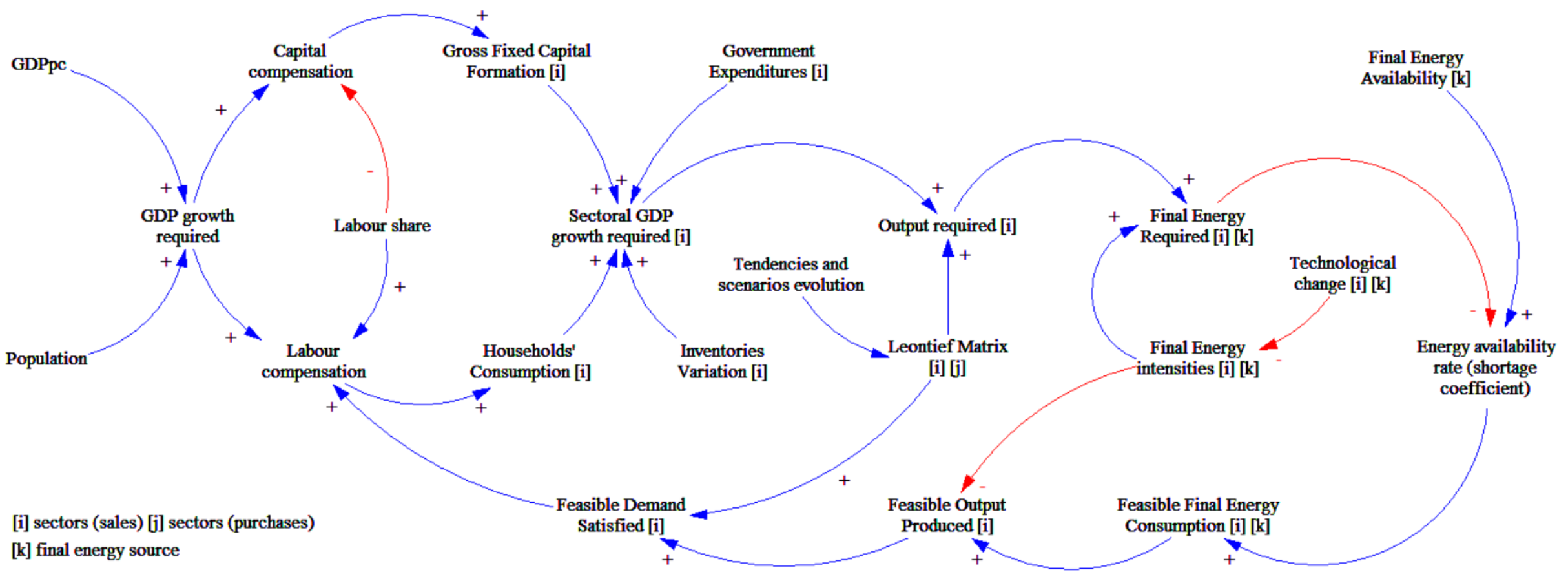

Figure 6. Simplified influence diagram of the Economy module.

Source: own elaboration. Red arrows imply negative relationship between variables; Blue arrows a positive relationship. 
According to this, inequality would increase across and within countries, so income distribution in this scenarios tends to increase the labour share. The more or less explicit objective is to undertake a modernisation process widely based on the path previously followed by developed countries, but including a technology-based transition to RER. Because of this, the A matrix, as a representation of the underlying technological structure, smoothly evolves towards Denmark's figures, as a developed European country highly committed to sustainability.

Lastly, we propose a third Post-Growth (PG) scenario. There is no explicit consensus on what a Post-Growth scenario means on the literature, but a well-known set of policies can be identified in ecological macroeconomics models (Hardt and O’Neil, 2017) as well as some assumptions that can be linked to a 'Regional Sustainable Development' narrative (van Vuuren et al., 2012). Because GDP growth is ruled out as the most important policy objective, economic growth slowly declines whereas other policy objectives are being pursued. This way, medium population growth along with the possibility of rapid technoligical change and proactive environmental protection, as well as a reduction of income inequality are applied to this scenario. Therefore, we implement a planned degrowth in the GDPpc targets, and income distribution leans towards labour compensation more than in GG. Likewise, the economic structure (represented by the A Matrix) changes favouring (penalising) the less (most) energy intensive sectors (see Appendix A and section 4.2). This approach is based on the procedures used by Leontief and Duchin (1986), whereby expected reductions or increases in relative demand for sectoral productive processes are represented by changing A matrix rows (i.e., sales proportion over each sector's output). Regarding energy, the figures are comparable to those in the GG scenario, but with reduced bioenergy growth to reduce competition pressures with other land uses and the phasing-out of nuclear energy in order to reduce as much as possible the NRER requirements.

Assumptions regarding RER energy potentials and NRER depletion curves have been made for all the scenarios. The most relevant exogenous inputs regarding these scenarios are summarised in Table 1. The main results, according to these scenarios, are shown thereafter. 


\begin{tabular}{|c|c|c|c|c|c|c|}
\hline \multicolumn{2}{|l|}{ Variable } & $\begin{array}{l}\text { Business } \\
\text { as Usual }\end{array}$ & $\begin{array}{l}\text { Green } \\
\text { Growth }\end{array}$ & $\begin{array}{l}\text { Post- } \\
\text { Growth }\end{array}$ & \multicolumn{2}{|c|}{ All scenarios } \\
\hline \multicolumn{7}{|c|}{ SOCIOECONOMIC } \\
\hline & $1.42 \%$ & $2.55 \%$ & $-0.67 \%$ & & \\
\hline \multirow{2}{*}{\multicolumn{2}{|c|}{$\begin{array}{l}\text { Population growth * } \\
\text { Target labour share (2050) }\end{array}$}} & $0.72 \%$ & $0.61 \%$ & $0.76 \%$ & & \\
\hline & & $52 \%$ & $60 \%$ & $65 \%$ & & \\
\hline \multicolumn{2}{|c|}{ Target A matrix (2050) $* *$} & $\begin{array}{l}\text { Historical } \\
\text { evolution }\end{array}$ & $\begin{array}{l}2009 \\
\text { Denmark } \\
\text { IOT }\end{array}$ & $\begin{array}{l}\text { Non } \\
\text { energy- } \\
\text { intensive }\end{array}$ & & \\
\hline \multicolumn{2}{|c|}{$\begin{array}{l}\text { Phase-out oil for electricity } \\
\text { and heat? }\end{array}$} & No & Yes & Yes & & \\
\hline \multicolumn{2}{|c|}{$\begin{array}{l}\text { Energy efficiency gains (max. } \\
\text { yearly growth) }\end{array}$} & $1 \%$ & $1.5 \%$ & $1.5 \%$ & & \\
\hline \multirow{2}{*}{\multicolumn{2}{|c|}{$\begin{array}{l}\text { Afforestation programme? } \\
\text { Nuclear installed capacity }\end{array}$}} & No & Yes & Yes & & \\
\hline & & Constant & Growth & Phase-out & & \\
\hline \multicolumn{2}{|l|}{ ENERGY } & \multicolumn{3}{|c|}{ Annual growth } & $\begin{array}{l}\text { Maximum } \\
\text { energy } \\
\text { potentials }\end{array}$ & References \\
\hline \multirow{7}{*}{$\begin{array}{l}\text { Electrical RER } \\
\text { capacity } \\
\text { installed } \\
\text { growth }\end{array}$} & Hydro & $2.8 \%$ & $5.6 \%$ & $5.6 \%$ & $1 \mathrm{TWe}$ & \multirow{11}{*}{$\begin{array}{l}\text { (de Castro et } \\
\text { al., 2011, } \\
2013,2014 \text { ) }\end{array}$} \\
\hline & Geot & $2.4 \%$ & $4.8 \%$ & $4.8 \%$ & $0.3 \mathrm{TW}$ th & \\
\hline & Bio & $7.2 \%$ & $14.4 \%$ & $14.4 \%$ & & \\
\hline & Oceanic & $4.8 \%$ & $20.0 \%$ & $20.0 \%$ & $0.05 \mathrm{TWe}$ & \\
\hline & \multirow{2}{*}{ Wind } & $25.1 \%$ & $30.0 \%$ & $30.0 \%$ & $1 \mathrm{TWe}$ & \\
\hline & & $41.0 \%$ & $41.0 \%$ & $41.0 \%$ & $0.25 \mathrm{TWe}$ & \\
\hline & Solar PV & $35.0 \%$ & $35.0 \%$ & $35.0 \%$ & & \\
\hline \multirow{4}{*}{ Bioenergy } & $2^{\text {nd }} \mathrm{Gen}$ & $11.0 \%$ & $20.0 \%$ & $15.0 \%$ & $0.95 \mathrm{TW}$ & \\
\hline & $\begin{array}{l}3^{\text {rd }} \text { Gen } \\
\text { (starting } \\
\text { 2025) }\end{array}$ & $11.0 \%$ & $20.0 \%$ & $15.0 \%$ & $0.95 \mathrm{TW}$ & \\
\hline & Residues & $11.0 \%$ & $20.0 \%$ & $20.0 \%$ & $0.79 \mathrm{TW}$ & \\
\hline & Biogas & $15.0 \%$ & $20.0 \%$ & $20.0 \%$ & 0,16 TW & \\
\hline \multirow{4}{*}{$\begin{array}{l}\text { NRER } \\
\text { depletion } \\
\text { curves }\end{array}$} & Oil & \multicolumn{5}{|c|}{ 'Middle' (Laherrère, 2006) } \\
\hline & Gas & \multicolumn{5}{|c|}{ 'Best Guess' (Laherrère, 2010) } \\
\hline & Coal & \multicolumn{5}{|c|}{ Best Guess (Mohr et al., 2015) } \\
\hline & Uranium & \multicolumn{5}{|c|}{ (Zittel and Schindler, 2006) } \\
\hline
\end{tabular}

Table 1. Overview of the most relevant scenario inputs. Source: own elaboration.

* Simulation period average value.

** See Appendix B.

Although the scenario design is partially based on qualitative assumptions from the literature (O'Neill et al., 2017; Riahi et al., 2017), the BAU can be summarised as a projection of current trends and Post-growth as a scenario not often considered in the literature; while Green Growth is the most akin to its homologous version in the literature (i.e., SSP2 from IPCC). 


\subsection{Emissions and GDP growth under energy constraints}

The variation in emissions has been estimated up to 2030 and 2050, as the former is the reference year for the Paris Agreement and the latter is the reference year for the IPCC reports. The base year is the average emissions from 2005-2015, since the Paris Agreement commitments (more than 160 INDCs) vary their base year within the mentioned range. Moreover, in order to evaluate the relevance of including energy limits, results have been assessed both considering (labelled as 'Limits' in graphs) and disregarding energy limits (labelled as 'No limits'). The difference between both assumptions is operated by activating or deactivating geological limits. Figure 7 shows emission outcomes by scenarios. Firstly, it does not matter whether we assume energy limits or not in the no policies scenario (BAU), as it dramatically fails to achieve climate goals. In this respect, the green growth scenario (GG) outcomes are substantially different if we activate the energy-economy feedback, i.e. geological limits are enabled, at least by 2050. Should the economy be able to take as much energy as needed regardless of its availability, emissions would even change their sign as compared to the same scenario when the energy-economy feedback is considered. There are no evident differences by $2030(\approx+14 \%)$, as no significant energy shortages appear until afterwards that date. However, by 2050, if the economy finds no obstacles in its consumption of as much energy as required to grow at a certain rate, emissions would rise by $51 \%$.

As stated in Eq.10, energy demand depends upon GDP growth, energy intensities (both sectoral and household) and economic structure (represented by the Leontief matrix). Whereas energy intensities and the economic structure are increasingly efficient 2 reducing the restraining effect of energy the higher GDP growth (see Table 2)expands final energy demand, eventually offsetting the efficiency gains and leading to energy scarcity as well. As a consequence, GDP growth is also hampered, although later than in BAU (Figure 8). On account of this rebound effect in the GG scenario, the energy system needs to draw on NRER for a longer period, even considering the high rate at which RER infrastructures are deployed (see Table 2). Conversely, as soon as energy limits are taken into account, results vary substantially. As can be seen in Figure 7 , emissions fall by around $16 \%$, although still far from meeting IPCC goals to avoid a $2^{\circ} \mathrm{C}$ increase $(-41 \%$ to $-72 \%)$. Contrary to the previous case, the final energy demand is not always satisfied, resulting in lower energy consumption and hence lower emissions. In addition to NRER exhaustion, as RER infrastructures gain momentum in the energy mix, the system's EROEI

${ }^{2}$ Producing the same amount of economic output allows a higher value added (GDP) to be obtained or, conversely: in order to obtain the same GDP, less production is required. See Appendix B (Target matrices). 
declines. Subsequently, a higher installed capacity for the same energy demand is required (see section 3.1.3.1). To sum up, a relatively high GDP growth forces energy demand up, offsetting efficiency gains and a more efficient economic structure. Because the final energy supply flow is not able to meet the final energy demand, energy consumption is lower, leading to better climate outcomes. In other words, emissions are reduced at the cost of depleting energy resources.

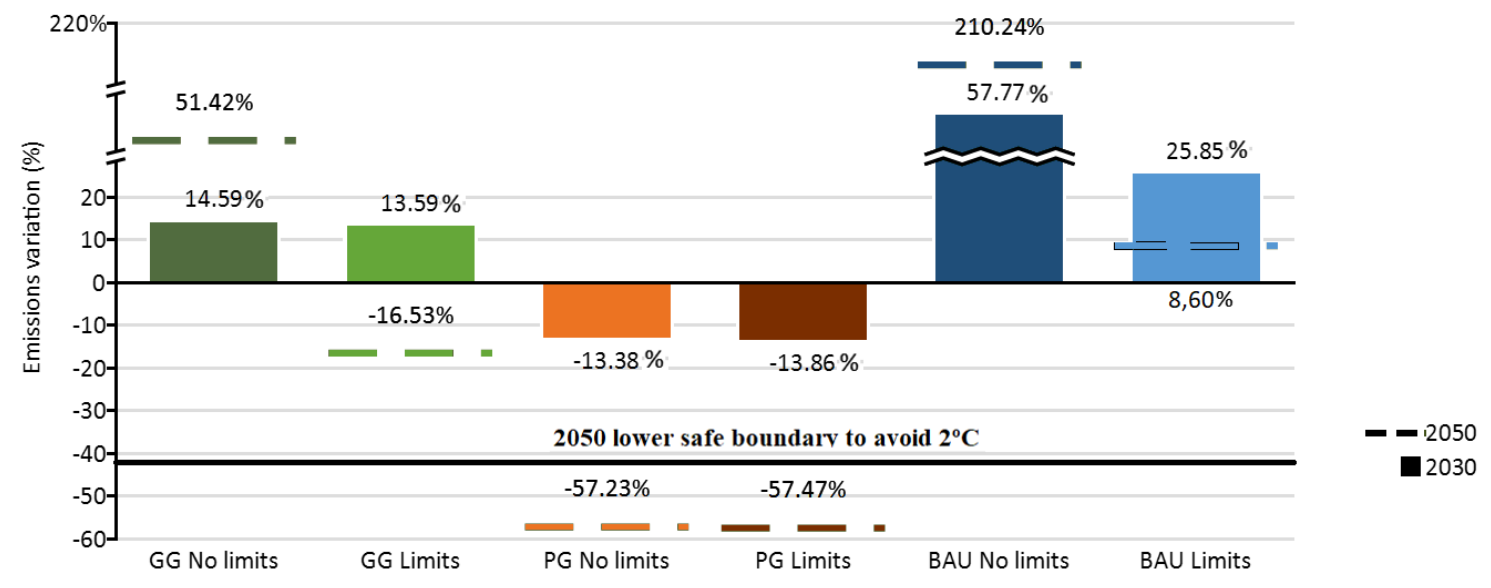

Figure 7. Emissions change by scenarios. From 2005-2015 mean to 2030 and 2050.

Note: GG: Green Growth scenario; PG: Post-Growth scenario; BAU: Business as Usual scenario.

Source: Own elaboration on the basis of MEDEAS World results.

Alternatively, the post-growth (PG) scenario remains entirely below the $2^{\circ} \mathrm{C}$ threshold in both cases $(\approx-57 \%)$. As verified by the GG scenario, a huge drop in energy intensities and a more efficient economic structure is not enough to downsize final energy demand. To overcome this hurdle, the PG scenario drops energy intensities just the same, but estimates a different, more efficient A matrix and a declining GDP growth (see Table 2 and Appendix B for Target matrices). To summarise, different outcomes amongst scenarios, especially between the GG and PG scenarios and the no policy scenario (BAU), are widely explained by the RER increase in the energy mix and the phasing-out of petroleum for heat and electricity. However, differences between GG and PG are mostly socioeconomic, reflected by different economic growth efforts, sectoral economic structures and functional income distribution.

Figure 8 shows the different outcomes for GDP growth regarding the figures in Table 1. The darker lines show exogenous GDP growth scenarios, i.e., disregarding the energy-economy feedback ('No Limits') and the lighter ones the results once the energy-economy feedback is activated ('Limits'). MEDEAS follows a metabolic approach whereby biophysical requirements are needed for throughput. Therefore, if higher energy supply is required for the expected GDP growth rate, then the economy will be able to grow lower than expected. As a consequence, in the 
absence of any further energy transition policies (BAU), the economy might stagnate within the next decade and start a sustained downsizing afterwards. As there is no phasing-out of oil for heat and electricity, the liquid energy potential could fail to meet the economic system's demand even at an early stage, leading to the collapse of economic output. Since there are no policies aimed at actively improving energy efficiency or changing the energy mix, economic growth is not able to recover during the simulation, as it faces subsequent resources scarcities -specially solids (coal)after the initial liquids shortage.

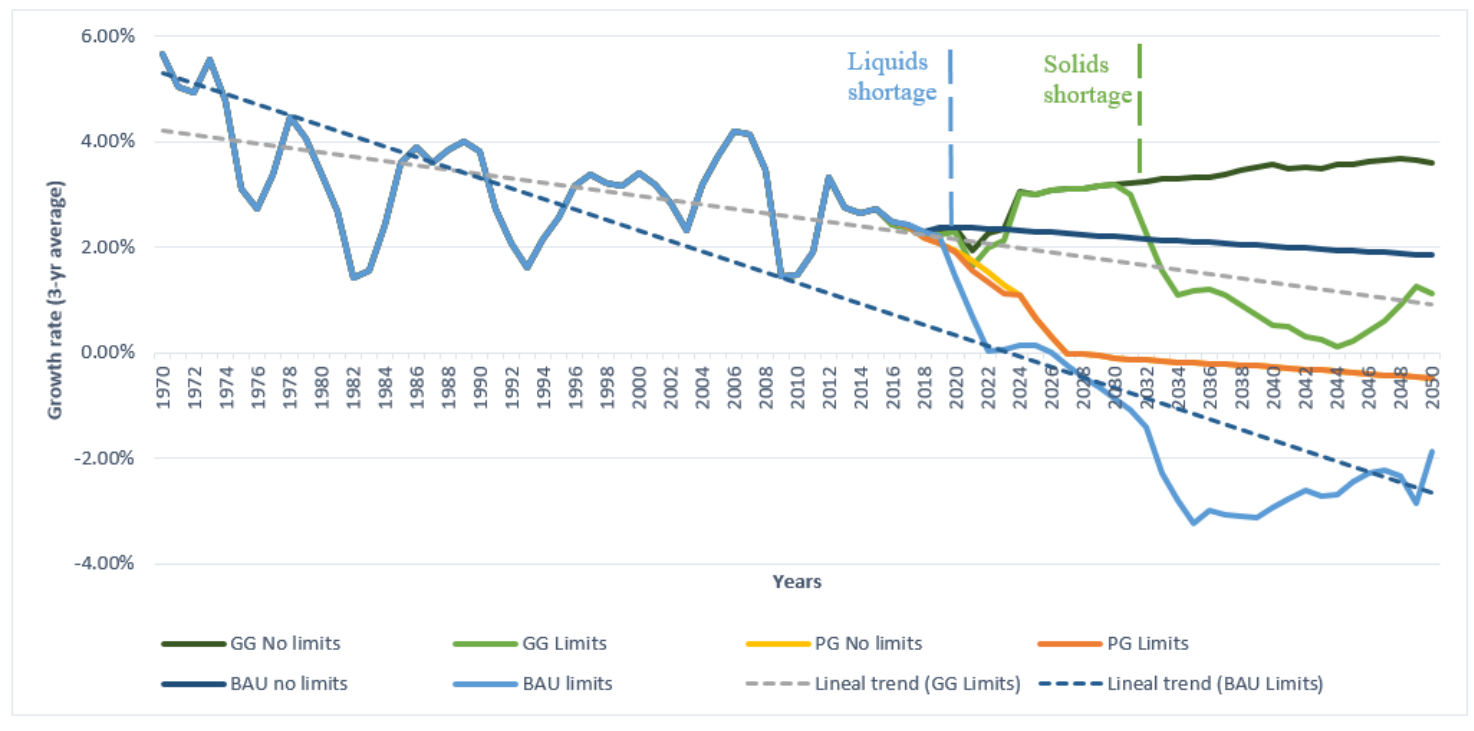

Figure 8. GDP growth scenarios (3-yr mobile average).

Source: own elaboration on the basis of MEDEAS World results.

Furthermore, should the Paris Agreement policies be undertaken (GG scenario) within the next decades, economic growth would be compatible with a rapid energy transition, at least until the mid-2030s. There is a solids shortage which hinders economic growth from maintaining its trend, although still not enough to stop increasing output. In other words, the economic activity will demand such an amount of final energy provided by liquids that the energy system will not be able to deliver. Thus, if the total output cannot be produced, the final demand is not fully satisfied, undermining GDP growth. By the end of the simulation period, GDP growth seems to be recovering. What this means is that once energy scarcity begins to determine the potential economic output, the constraint can be more or less severe regarding the shortage coefficient. Nevertheless, both BAU and GG trends lead, at the very least, to a slow-growth regime in the next few decades to come. 
What MEDEAS captures is not a sudden or dramatic energy crisis such as the 70's oil crisis, driven by geopolitical and institutional reasons. Rather, a lack of energy supply is posing a decline in the economy's capacity to increase throughput that might hinder economic growth and drive the global economy to stagnation. In the low-carbon transition, time matters and this is captured by MEDEAS. It takes energy to deploy the renewable energy infrastructures and at the earlier stage this will need to be carried out with a high proportion of NRER in what has been called the 'energy trap' (Sers and Victor, 2018) or, put it in other words, the 'Sower's way' referred to net energy availability (Sgouridis, Csala and Bardi, 2016). Certainly, the geographic coexistence of different metabolic regimes could strengthen this tendency. In fact, not by chance the Paris Agreement only imposes a carbon reduction to the High Income countries and allows huge carbon increases in the lower income countries. The use of NRER will potentially remain an important share of the energy mix in the years to come, especially in Middle Income countries. Given the increasing cost (both in energy and economic terms) of their extraction due to the reduction in the accessibility of the better resources, the development process of the so-called 'emergent countries' could be hampered and might potentially lead to geostrategic conflicts.

In this context of a slowing GDP growth, a trend that can even be noticed by just taking the historical data, the PG scenario implies an adaptive approach which attains climate goals. The downsizing of economic growth is conducted in a steady way, with neither considerable fluctuations, nor abrupt collapses, whereas income distribution is improved. Essentially, whilst GG scenarios have to face involuntary economic downsizing and energy source depletion just to achieve an insufficient emissions reduction, the PG scenario widely meets climate goals without facing the huge cost of non-planned, disruptive, plummeting economic output. Moreover, an economic system which pushes NRER reserves down less allows the whole system to retain a larger amount of these resources underground. In this context, policies aimed at maintaining welfare, or increasing it in the case of developing countries, would be of the utmost important if the energy transition is to be completed on a fair and equal basis. For this purpose, it is fundamental a decoupling between welfare and economic growth. A new set of Post-Growth policies could be useful to achieve socioeconomic goals along with the climate targets. We explore further on that in section 5.

As long as energy feedbacks are not included in models, their outcomes might be flawed, suggesting that economic output could be increased without limits. Standard production functions, even if considering energy (or, more generally, natural resources) as a production factor, could at best capture relative reductions on its positive slope. On the one hand, the assumption of perfect substitutability of production factors allows conventional models to 
counterbalance energy constraints by adding more of the other inputs (namely, capital and labour). On the other hand, by considering natural resources (natural capital) as one more input, their depletion (depreciation) can theoretically be corrected by new investment, omitting the irreversibility of environmental impacts. System dynamics and its stock and flow, feedback-rich structure allow the model to capture energy boundaries that the economy cannot surpass. Once energy constraints are integrated into the model, the results show that climate goals could only be met by keeping economic growth as a policy objective at a high socioeconomic cost (output collapse) and the depletion of NRER. What this suggests is a growth-mitigation paradox, where the only reason why climate goals are barely met in the GG scenario is because an economic collapse occurs during the simulation period. What this result might suggest is that most EnergyEconomy-Environment models could be inaccurately specifying energy-economy interactions.

Nonetheless, when scarcity becomes significant ( $\varepsilon \cong 0.98$ or lower), the liquids scarcity stands out above the other resources. The NRER extraction rate is no longer high enough to meet the economic growth rates the world is used to, or those that the so-called non-developed countries would require to follow the development pathways previously undertaken by rich countries. What is more, high economic growth might not even be a feasible option for the future, regardless of whether the energy transition is completed or not. Furthermore, as long as climate impacts are disregarded in this analysis, the GDP outcomes could be expected to be worsened in the scenarios with higher GHG emissions.

\subsection{Structural change and the uncertain pathways towards sustainability}

The economic structure is a key issue in sustainability transitions. The economic system consists of several sub-economies, each of them with their own interrelated rationales. Here, the economy has been divided into 35 different industries (see Appendix A), according to WIOD (Dietzenbacher et al., 2013). As stated in section 3.1.2, the total final demand provided by scenarios unfolds disparately amongst the 35 sectors. What is more, whether this demand is made by household consumption or by gross fixed capital formation (investments) depends on income distribution (see section 3.1.1).

As described in Eq. 10, energy demand depends on the economic structure (L), energy intensities ( $\hat{\mathrm{e}}_{k}$ ) and final demand $(D)$. Thus, the column sum of the result of pre-multiplying $\hat{\mathrm{e}}_{k}$ by $L$ yields the energy multipliers shown in Table 2 for 2009 . These multipliers can be interpreted as the sectoral energy sensitivity to final demand (GDP) growth by final end-use energy carrier. For instance, it takes 1.260 EJ of electricity to satisfy 1 trillion USD of additional final demand

for sector 1 (see Table 1) products. Thus, having a less energy-intensive economy, measured as 
the energy consumption required to satisfy the same GDP, relies on energy intensity and economic structure. Hence, a less energy-intensive economy could be achieved through reductions in energy intensity (efficiency gains), a less input-consuming productive process (downsizing the overall values of $a_{i j}$ in the A Matrix) or, conversely, an increase in one of them not high enough to offset the reduction in the other.

\begin{tabular}{|c|c|c|c|c|c|}
\hline Sector & Electricity & Gas & Heat & Liquids & Solids \\
\hline 1 & 1.260 & 0.802 & 0.173 & 3.996 & 0.757 \\
\hline 2 & 1.907 & 5.580 & 0.308 & 2.179 & 1.737 \\
\hline 3 & 1.430 & 1.147 & 0.293 & 2.917 & 1.925 \\
\hline 4 & 2.135 & 1.317 & 0.525 & 2.601 & 1.647 \\
\hline 5 & 1.482 & 1.049 & 0.335 & 2.603 & 1.355 \\
\hline 6 & 1.909 & 1.208 & 0.423 & 2.985 & 2.786 \\
\hline 7 & 2.218 & 1.365 & 0.515 & 2.045 & 2.911 \\
\hline 8 & 2.071 & 5.170 & 1.017 & 10.005 & 1.788 \\
\hline 9 & 2.858 & 2.997 & 1.055 & 3.353 & 2.168 \\
\hline 10 & 3.446 & 2.539 & 0.670 & 3.913 & 3.972 \\
\hline 11 & 3.414 & 3.362 & 0.362 & 4.062 & 10.724 \\
\hline 12 & 4.259 & 2.972 & 0.504 & 2.341 & 5.081 \\
\hline 13 & 1.858 & 1.276 & 0.267 & 1.822 & 1.798 \\
\hline 14 & 1.467 & 0.997 & 0.209 & 1.618 & 1.295 \\
\hline 15 & 1.731 & 1.195 & 0.276 & 1.830 & 1.584 \\
\hline 16 & 2.047 & 1.674 & 0.418 & 3.258 & 2.403 \\
\hline 17 & 3.958 & 4.320 & 0.394 & 1.841 & 3.451 \\
\hline 18 & 1.437 & 1.288 & 0.204 & 2.503 & 2.138 \\
\hline 19 & 0.904 & 0.597 & 0.127 & 1.477 & 0.553 \\
\hline 20 & 0.507 & 0.346 & 0.094 & 1.352 & 0.273 \\
\hline 21 & 0.797 & 0.463 & 0.089 & 1.645 & 0.280 \\
\hline 22 & 1.469 & 0.963 & 0.163 & 2.241 & 1.052 \\
\hline 23 & 1.070 & 2.384 & 0.139 & 7.855 & 0.609 \\
\hline 24 & 0.636 & 0.800 & 0.163 & 30.073 & 0.512 \\
\hline 25 & 0.715 & 0.914 & 0.182 & 28.052 & 0.566 \\
\hline 26 & 1.069 & 0.838 & 0.216 & 4.772 & 0.585 \\
\hline 27 & 0.638 & 0.514 & 0.082 & 1.193 & 0.305 \\
\hline 28 & 0.437 & 0.270 & 0.060 & 0.862 & 0.209 \\
\hline 29 & 0.500 & 0.264 & 0.082 & 0.503 & 0.220 \\
\hline 30 & 0.604 & 0.435 & 0.088 & 1.368 & 0.358 \\
\hline 31 & 1.005 & 1.230 & 0.126 & 1.773 & 0.503 \\
\hline 32 & 1.107 & 0.538 & 0.128 & 1.519 & 0.444 \\
\hline 33 & 0.942 & 0.645 & 0.162 & 1.625 & 0.525 \\
\hline 34 & 0.994 & 0.660 & 0.170 & 1.967 & 0.534 \\
\hline 35 & 0.171 & 0.374 & 0.027 & 0.279 & 0.146 \\
\hline
\end{tabular}

Table 2. Energy sensitivity to final demand growth by resources (EJ/trillion USD). Source: Own elaboration on the basis of WIOD and IEA. 
Table 3 provides useful information for policy-makers for selecting the appropriate sectors to undertake different policies. Despite industrial policy, i.e. the administration's encouragement of key sectors to the detriment of others, has been ruled out during the last decades, it emerges as a useful tool to achieve climate goals. Thus, industrial policy could focus on reducing the weight in the economy of the most energy-intensive sectors or increasing the less energy-intensive sectors as in the PG scenario (see Appendix B) In addition, it can be used to identify the most sensitive energy source to satisfy economic demand. For instance, energy carriers from liquids to increase GDP are the highest, especially in the transport sectors (23-25), fossil fuel refineries (8) and even the primary sector (1). These facts explain why liquid limits are the first to be significantly found and why it causes the deeper output impact when it occurs, when compared with other final end-use energy carriers such as solids.

By definition, the BAU scenario's assumptions make it considerably energy-demanding. Firstly, since energy transition policies are not as important as they are in the other scenarios, energy intensities decline slower. Secondly, if the technical coefficients (A matrix) were to evolve following the historical projection, the world might move towards a more inefficient economic system. As mentioned in section 3.1.3, the more intermediate products purchases required to produce each industry's output, the smaller the share remaining for the gross value added (wages and profits as it is measured at factor costs). Therefore, to avoid unrealistic outcomes, the A matrix in the BAU scenario is not allowed to decrease the value added beyond one third of its initial share by sector (see Appendix B).

Conversely, the Green Growth scenario experiences a higher energy intensity drop and the economy moves towards a more efficient structure. As the A matrix comes closer to Denmark's structure, obtaining the same GDP growth requires less production in each period. Nevertheless, a rebound effect appears due to the increased capacity of the economy to boost final demand. As a result, the efficiency gains are partially offset and total energy requirements increase by approximately $10 \%$ in 2030 , although it manages to decrease the mentioned requirements by $13 \%$ in 2050 (see Figure 9). Lastly, the Post-Growth scenario simulates an industrial policy focused on favouring less energy-intensive sectors such as, 'Education', 'Health and Social Work' or 'Other Community, Social and Personal Services', while disfavouring others like 'Coke, Refined Petroleum and Nuclear fuel', 'Air transport' or 'Chemicals and Chemical products'. This approach (Leontief and Duchin, 1986) allows the model to explore an energyfocused industrial transformation. As a result, along with a steady decline in GDP growth, the PG 
scenario decreases its total energy needs by $17 \%$ in 2030 and $44 \%$ in 2050 , according to the total effects shown in Figure 9.

Besides, Input-Output Analysis allows us to accurately differentiate between direct effects (those triggered by the variation in demand itself) and indirect effects (those activated by the spill-over to deliver intermediate inputs across industries) by energy resources (see Appendix C). Figure 9 shows the total contribution of both direct and indirect effects to energy growth, which always sum 100\%, as well as the total final energy demand variation by 2030 and 2050 (total effects, in dotted lines). The results shown in Figure 9 are only valid for simulations accounting with energy limits, so the energy use reported here is linked to the energy emissions and GDP growth shown in Figs. 7 and 8 labelled as 'Limits'. The bars with a positive value looking rightwards- indicate that the effect (direct or indirect) contributed to the total energy use change by 2050 with the same sign, and the other way around. For instance, in the GG scenario, the solids' use is $12 \%$ lower in 2050 . The indirect effects, i.e. the contribution of the intermediate products' trade flows between industries highly contributed to this reduction (partly due to the A matrix change and partly by the industries' energy efficiency gains). Conversely, the direct effects triggered by an increased final demand weakened the energy use reduction capacity of the indirect effects, so the total final decrease in solids' use is lower.

As an overall result, the significant importance of the contribution of indirect effects to the total energy demand variation, even pushing in the opposite direction to direct effects, underlines the relevance of integrating Input-Output Analysis into IAMs. This can be clearly seen in the PG scenario, where in spite of the direct contribution to reduce energy demand via a decline in GDP growth, indirect effects strongly oversize them. The shift in the intermediate structure of the economy accounts $57 \%$ of the responsibility in solids' use reduction (-50\%), 53\% in heat ($58 \%$ ) and $42 \%$ in liquids (-67\%). Moreover, the indirect effects are able to reduce electricity use despite the pressure to be increased by direct effects -bar looking leftwards while total effects being negative- in the context of a strong electrification process. The same can be applied to gases, considered a 'bridge' resource in the energy transition. As a consequence, we can conclude that without an important economic structure transformation, climate goals could hardly be met since GHG emissions are strongly linked to energy use (see Figure 7). The total effects show that the total energy demand is still increasing with the BAU $(+12 \%)$ and GG scenarios $(+10 \%)$ by 2030 ; whereas the PG is already declining $(-17 \%)$. This explains the inability of any scenario other than PG to reduce emissions before 2030 (Figure 7). 
The energy demand decline in the BAU scenario (2050) is mostly due to direct effects: the reduction in final demand imposed by energy scarcity would be the main driver of the energy demand downsizing. Nevertheless, for electricity demand, indirect and direct effects contribute to the energy demand variation in different ways resulting in an overall increase. The electricity use is increased by 2050 (8\%) basically due to the energy mix tendency to electrify and the more inefficient economic structure. As a consequence, electricity use increases despite the economic downturn which leads GDP (direct effects) to decrease. The relatively lower reduction in the liquids use and the lack of an intense shift in the electricity mix to renewables explain why GHG emissions (Fig.7) increase even though the economic system is in recession. The more inefficient A matrix structure leads the indirect effects to increase electricity demand, whereas energy intensities drop, bringing about an overall decline thanks to the direct effects. The contribution to the decline in energy demand in the GG scenario is also evident, with even a reduction in the energy demand in those resources that actually increased (electricity and gases). As mentioned before, the indirect effects were the main driver of the decline in energy demand in the postgrowth scenario, highlighting the relevance of industrial policy along with energy efficiency gains. 

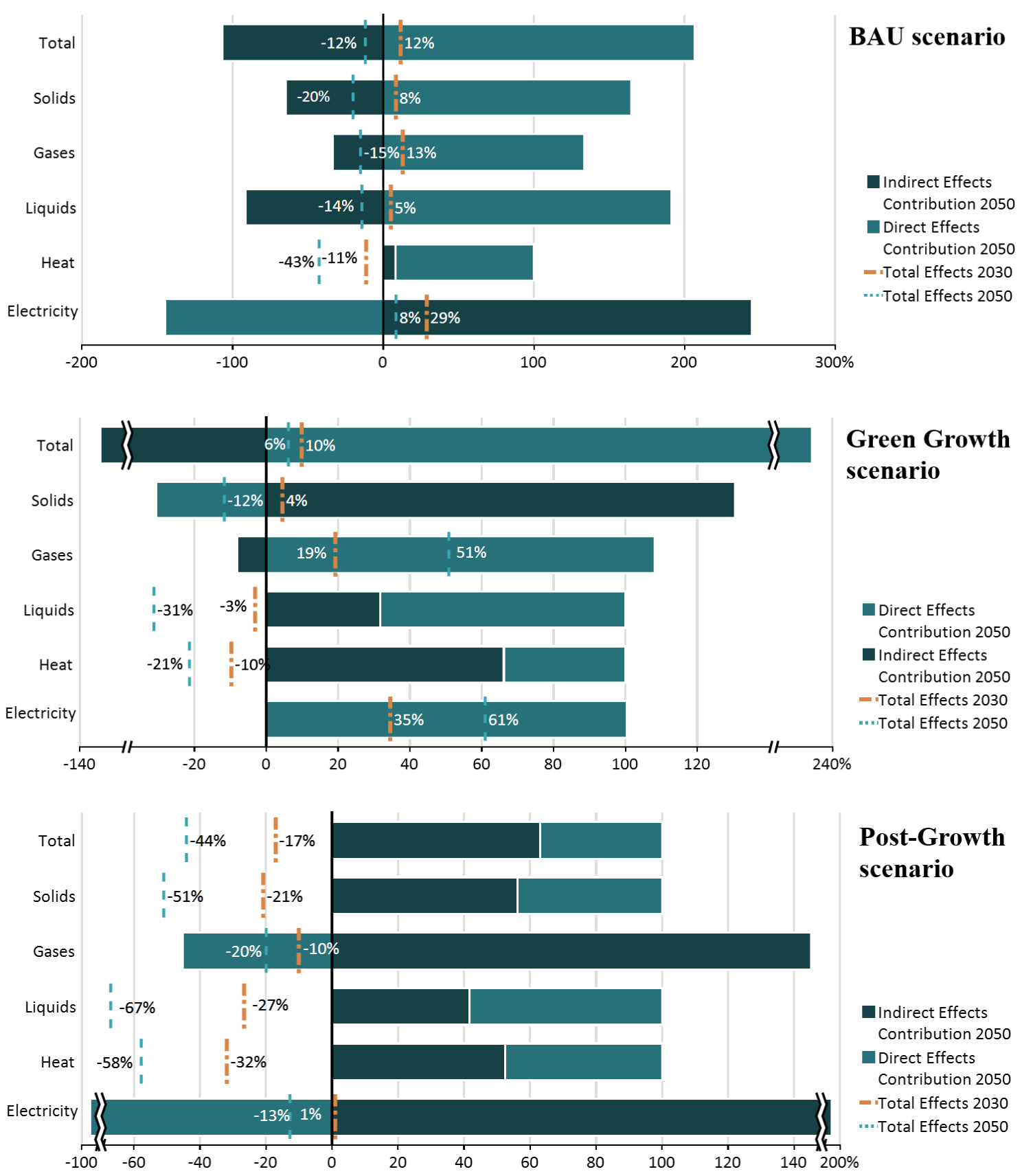

Figure 9. Direct and indirect contribution to energy demand variation by final end-use energy carriers and scenarios. 


\section{Concluding remarks and Policy Implications}

Within the last few decades, the need to include environmental aspects into macroeconomic modelling has drawn increasing academic attention. Considering that most of the carbon emissions are produced within the energy sector and regarding its nexus with economic growth, it makes sense to focus on Energy-Economy-Environmental models. The review of the literature reveals a lack of consideration in simulation models to the role of energy availability and its potential effect on limiting production in the economic system. What is more, there is a theoretical discussion on whether economic growth can be compatible with, or even boost, lowcarbon transitions. Since rapidly tackling climate change while keeping or improving wellbeing imposes an urgent agenda, more accurate outcomes from modelling and discussion on their policy implications is of the utmost importance. According to the IPCC, emissions should plummet from $-41 \%$ to $-72 \%$ by 2050 , with respect to 2010 , in order to make avoiding a world temperature increase of above $2^{\circ} \mathrm{C}$ 'likely'.

The results expose the unfeasibility of economic growth once biophysical constraints have been considered. Although the BAU scenario copes with energy limits at an early stage due to a lack of energy mix transition to renewables; this policy shows itself to be ineffective when the GDP growth rate is increased in the GG scenario. Essentially, the deployment time, diminishing EROEI and sectoral hurdles to switch to renewables collide with the growing energy requirements imposed by GDP growth. Thus, the energy system needs to draw on non-renewable energy resources to meet the increasing energy demand, which eventually becomes higher than the energy availability, resulting in a declining trend of the economic output. It is only after the economic slow-down that emissions start decreasing, but not soon enough to meet climate objectives. Conversely, a planned steady decline in GDP growth displayed by the PG scenario, along with industrial policy fostering less energy-intensive sectors, leads to better climate outcomes (well below $2^{\circ} \mathrm{C}$ ), while completing the energy transition and enhancing income distribution.

The implications for policy-makers lie in the scenario results. Firstly, the differences between the BAU and the other scenarios show that it might be better 'to do something' than 'to do nothing'. Should the energy transition not be undertaken soon with credible, strong policies by the countries, the world might face economic stagnation and then depression in the coming decades. Secondly, and perhaps more importantly, a mere technological energy switch to renewables could be unfeasible if not complemented with huge socioeconomic changes. As shown by the results, the economic costs of keeping GDP growth as the main objective of 
economic-policy could be too high to be socially affordable. Thus, we believe that economic policy should be redirected to redistributional and industrial policies. In addition, energy demand policies should not only aim at improving energy efficiency, but also designing multidisciplinary demand management policies intended to satisfy human needs by means of collectively less energy-intensive ways. Short distribution channels, a switch from modern to traditional or ecological agriculture and farming, favouring public and collective transport and planning industrial ecology developments, amongst other policies, might contribute to human well-being in an energy and GDP declining context. Also, focusing on more labour intensive sectors such as education, health care or social work together with working time reduction policies could be important to address employment in a low-carbon economy.

It certainly raises deep theoretical implications and further challenges for development economics, ecological economics, well-being and economic analysis in general. First, although it becomes ineffective to deliver well-being beyond a certain level of economic growth (Jackson, 2011), most non-developed countries have not yet reached that threshold. Thus, development studies may need to lean towards non-extractivist, post-growth approaches in order to achieve the most meaningful results possible. The reduction of economic output, either planned or unplanned, suggests the need to implement regional redistribution policies to improve the welfare of developing countries. Moreover, economic growth theory should include biophysical boundaries that fit reality better. The MEDEAS model shows that economic growth might be unachievable in the context of the energy challenges that the world urgently needs to tackle. As a consequence, macroeconomic modelling should consider absolute biophysical constraints if more accurate outcomes are to be obtained. Conventional production functions could be failing to capture these absolute restraints by compensating for natural capital depletion with capital accumulation, labour growth, or even the so-called total factors productivity. Therefore, if models only include the environment as theoretical categories -such as 'natural capital' or 'ecosystem services'- which can be eroded but restored, they could be disregarding irreversibility in natural systems and thus obtaining misleading results. Furthermore, there is a lack of high, two-way integration between the economy and the biophysical system in IAMs that MEDEAS could contribute to cover. More complex insights are required to better represent the real world dynamics, subject to irreversibility when the consumption of resources is being assessed.

Finally, in order to improve the accuracy of the economic model, further developments should be addressed in the future. Firstly, the full endogenisation of inequality could enhance the final demand estimation, setting the basis to include the financial structure in the model. The latter will allow the model to analyse the financial requirements of the energy transition by tracking 
more accurately the investment flows to the energy-related sectors. Secondly, the endogenous A matrix evolution, linked to the energy mix transition and technological change, would be a great step forward in the dynamic representation of the economic structure in the model. This would also contribute to enhance the linkage between the energy mix and energy-related sectors in the IOT. Thirdly, considering this, demand management policies should be measured and then implemented in the model. Thus, an effective decoupling between well-being and GDP growth could be assessed.

\section{Acknowledgements}

We are grateful for the support in the elaboration of this article from the European project H2020-LCE-2015-2 (691287) Guiding European Policy toward a low-carbon economy. Modelling Energy System Development under Environmental and Socioeconomic constraints (MEDEAS). We are thankful as well for the support of MODESLOW project: MODElling and Simulation of scenarios towards a LOW-carbon transition: the Spanish case). A Spanish national research project (ECO2017-85110-R) funded under the Spanish National Research, Development and Innovation Program (Ministry of Economy and Innovation, Spain). We are thankful for the work developed within the Research Group on Energy, Economy and System Dynamics.

\section{References}

Alcamo, J., Leemans, R. and Kreileman, E. (1998) Global change scenarios of the 21st century: results from the IMAGE 2.1 model. Tarrytown, N.Y.: Pergamon.

Bardi, U. (2011) The limits to growth revisited. Springer.

Barlas, Y. (1996) 'Formal aspects of model validity and validation in system dynamics', System Dynamics Review. John Wiley \& Sons, Ltd, 12(3), pp. 183-210. doi: 10.1002/(SICI)10991727(199623)12:3<183::AID-SDR103>3.0.CO;2-4.

Bernardo, G. and D'Alessandro, S. (2014) 'Transition to sustainability? Feasible scenarios towards a low-carbon economy', MPRA Paper. University Library of Munich, Germany. Available at: https://ideas.repec.org/p/pra/mprapa/53746.html (Accessed: 24 June 
2019).

Bernardo, G. and D’Alessandro, S. (2016) 'Systems-dynamic analysis of employment and inequality impacts of low-carbon investments', Environmental Innovation and Societal Transitions, 21(Supplement C), pp. 123-144. doi: 10.1016/j.eist.2016.04.006.

Bouwman, A., Kram, T. and Goldewijk, K. K. (2006) Integrated modelling of global environmental change: an overview of IMAGE 2.4. Bilthoven: Netherlands Environmental Assessment Agency.

Bowen, A. and Hepburn, C. J. (2012) Prosperity with Growth: Economic Growth, Climate Change and Environmental Limits. Rochester, NY. Available at: https://papers.ssrn.com/abstract=2575804 (Accessed: 17 April 2018).

Briens, F. (2015) 'Investigating Pathways to Post-Growth Economies Through Prospective Macroeconomic Modeling: Vision and Scenarios for France.', in. Leeds.

Capellán-Pérez, I. et al. (2015) 'More growth? An unfeasible option to overcome critical energy constraints and climate change', Sustain Sci, 10(3), pp. 397-411. doi: 10.1007/s11625015-0299-3.

Capellán-Pérez, I. et al. (2017) Global Model: MEDEAS- World Model and IOA implementation at global geographical level. Available at: https://www.medeas.eu/system/files/documentation/files/Deliverable 4.1 \%28D13\%29_Global Model.pdf.

Capellán-Pérez, Í. (2016) Development and Application of Environmental Integrated Assessment Modelling towards Sustainability. University of País Vasco.

de Castro, C. et al. (2011) 'Global wind power potential: Physical and technological limits', Energy Policy. (Sustainability of biofuels), 39(10), pp. 6677-6682. doi: 10.1016/j.enpol.2011.06.027. 
de Castro, C. et al. (2013) 'Global solar electric potential: A review of their technical and sustainable limits', Renewable and Sustainable Energy Reviews, 28, pp. 824-835. doi: 10.1016/j.rser.2013.08.040

de Castro, C. et al. (2014) 'A top-down approach to assess physical and ecological limits of biofuels', Energy, 64, pp. 506-512. doi: 10.1016/j.energy.2013.10.049.

Cordier, M. et al. (2017) 'An Input-output Economic Model Integrated Within a System Dynamics Ecological Model: Feedback Loop Methodology Applied to Fish Nursery Restoration', Ecological Economics, 140, pp. 46-57. doi: 10.1016/j.ecolecon.2017.04.005.

Costanza, R. (1989) 'What is ecological economics?', Ecological Economics, 1(1), pp. 1-7. doi: 10.1016/0921-8009(89)90020-7.

Costanza, R. (1991) Ecological Economics: The Science and Management of Sustainability. Revised ed. New York: Columbia University Press.

Csereklyei, Z. and Stern, D. I. (2015) ‘Global energy use: Decoupling or convergence?', Energy Economics, 51, pp. 633-641. doi: 10.1016/j.eneco.2015.08.029.

D’Alessandro, S., Luzzati, T. and Morroni, M. (2010) 'Energy transition towards economic and environmental sustainability: feasible paths and policy implications', Journal of Cleaner Production, 18(4), pp. 291-298. doi: 10.1016/j.jclepro.2009.10.015.

D’Alisa, G., Kallis, G. and Federico, D. (2014) Degrowth: A Vocabulary for a New Era. 1 edition. New York; London: Routledge.

Daly, H. (1968) 'On economics as a life science', Journal of Political Economy, 76(3), pp. $392-406$.

Daly, H. E. (1973) Toward a steady-state economy. W.H. Freeman.

Dietz, R. and O’Neill, D. (2013) Enough Is Enough: Building a Sustainable Economy in 
a World of Finite Resources. 1 edition. San Francisco: Berrett-Koehler Publishers.

Dietzenbacher, E. et al. (2013) ‘THE CONSTRUCTION OF WORLD INPUT-OUTPUT TABLES IN THE WIOD PROJECT', Economic Systems Research, 25(1), pp. 71-98. doi: 10.1080/09535314.2012.761180.

Dowlatabadi, H. (1998) 'Sensitivity of climate change mitigation estimates to assumptions about technical change.', Energy Economics, 20, pp. 473-493. doi: 10.1016/S01409883(98)00009-7.

Farley, J. and Daly, H. E. (2003) Ecological Economics: Principles and Applications. 1 edition. Washington: Island Press.

Fischer-Kowalski, M. (2011) 'Analyzing sustainability transitions as a shift between socio-methabolic regimes', Environmental Innovation and Societal Transitions., 1, pp. 152-159.

Fischer-Kowalski, M. and Haberl, H. (2007) Socioecological transitions and global change : trajectories of social metabolism and land use. Edward Elgar.

Fontana, G. and Sawyer, M. (2016) 'Towards post-Keynesian ecological macroeconomics', Ecological Economics. Elsevier, 121, pp. 186-195. doi: 10.1016/J.ECOLECON.2015.03.017.

Foxon, T. J. (2017) Energy and Economic Growth: Why we need a new pathway to prosperity. 1 edition. Abingdon, Oxon ; New York, NY: Routledge.

Geels, F. (2002) 'Technological transitions as evolutionary reconfiguration processes: a multi-level perspective and a case-study', Research Policy, 8/9(31), pp. 1257-1274.

Geels, F. W. (2011) 'The multi-level perspective on sustainability transitions: Responses to seven criticisms', Environmental Innovation and Societal Transitions. Elsevier, 1(1), pp. 24 40. doi: 10.1016/J.EIST.2011.02.002. 
Genty, A. (2012) 'Final database of environmental satellite accounts: technical report on their compilation'. WIOD Deliverable 4.6, Documentation. Available at: http://www.wiod.org/publications/source_docs/Environmental_Sources.pdf.

Georgescu-Roegen, N. (1971) The Entropy Law and the Economic Process. Harvard University Press.

Georgescu-Roegen, N. (1975) 'Dynamic models and economic growth', World Development, 3(11), pp. 765-783. doi: 10.1016/0305-750X(75)90079-0.

De Haan, M. (2001) 'A Structural Decomposition Analysis of Pollution in the Netherlands', Economic Systems Research, 13(2), pp. 181-196. doi: http://dx.doi.org/10.1080/09537320120052452.

Haberl, H. et al. (2011) 'A Socio-metabolic Transition towards Sustainability?', Challenges for Another Great Transformation, 19, pp. 1-14.

Hall, C. A. S. and Klitgaard, K. (2012) Energy and the Wealth of Nations: Understanding the Biophysical Economy. New York: Springer-Verlag. Available at: //www.springer.com/us/book/9781441993984 (Accessed: 17 April 2018).

Hardt, L. and O’Neill, D. W. (2017) ‘Ecological Macroeconomic Models: Assessing Current Developments', Ecological Economics, 134, pp. 198-211. doi: 10.1016/j.ecolecon.2016.12.027.

Hein, E. and Ochsen, C. (2003) 'Regimes of Interest Rates, Income Shares, Savings and Investment: A Kaleckian Model and Empirical Estimations for some Advanced OECD Economies', Metroeconomica, 54(4), pp. 404-433. doi: 10.1111/1467-999X.00173.

IPCC (2014) IPCC Fifth Assessment Synthesis Report. Geneva.

Jackson, T. (2011) Prosperity without Growth: Economics for a Finite Planet. Reprint 
ed. London; Washington, DC: Routledge.

James, D. E., Jansen, H. M. A. and Opschoor, J. B. (1978) Economic Approaches to Environmental Problems. Amsterdam: Elsevier North Holland.

Kainuma, M. (2003) Climate policy assessment: Asia-Pacific integrated modeling. Tokyo: Springer.

Kander, A. and Stern, D. I. (2014) 'Economic growth and the transition from traditional to modern energy in Sweden', Energy Economics, 46, pp. 56-65. doi: 10.1016/j.eneco.2014.08.025.

Kemfert, C. (2005) 'Induced technological change in a multi-regional, multi-sectoral, integrated assessment model (WIAGEM): Impact assessment of climate policy strategies.', Ecological Economics, 54, pp. 293-305. doi: 10.1016/j.ecolecon.2004.12.031.

Kerschner, C. (2010) 'Economic de-growth vs. steady-state economy', Journal of Cleaner Production. (Growth, Recession or Degrowth for Sustainability and Equity?), 18(6), pp. 544-551. doi: 10.1016/j.jclepro.2009.10.019.

Kiuila, O. (2018) 'Decarbonisation perspectives for the Polish economy', Energy Policy, 118, pp. 69-76. doi: 10.1016/j.enpol.2018.03.048.

Laherrère, J. (2006) 'Oil and gas, what future? Presented at the Groningen annual Energy Convention', in. Groningen, Netherlands.

Laherrère, J. (2010) 'Peak Oil and Energy Security. Presented at the Segundo Simposio ASPO Argentina’, in. Buenos Aires, Argentina.

Lange, S. (2018) Macroeconomics Without Growth: Sustainable Economies in Neoclassical, Keynesian and Marxian Theories. Marburg: Metropolis Verlag.

Lavoie, M. (1995) 'Interest Rates in Post-Keynesian Models of Growth and Distribution', 
Metroeconomica, 46(2), pp. 146-177. doi: 10.1111/j.1467-999X.1995.tb00375.x.

Lavoie, M. (2014) Postkeynesian Economics: New Foundations. Chentelham: Edward Elgar.

Leontief, W. (1970) 'Environmental Repercussions and the Economic Structure: An Input-Output Approach', The Review of Economics and Statistics, 52(3), pp. 262-271. doi: $10.2307 / 1926294$.

Leontief, W. and Duchin, F. (1986) The future impact of automation on workers. Oxford University Press. Available at: https://econpapers.repec.org/bookchap/oxpobooks/9780195036237.htm (Accessed: 24 June 2019).

Markaard, J., Raven, R. and Truffer, B. (2012) 'Sustainability transitions: An emerging field of research and its prospects', Research Policy, 41, pp. 955-967.

Masui, T. et al. (2006) 'Assessment of $\mathrm{CO}_{3}$ Reductions and Economic Impacts Considering Energy-Saving Investments', The Energy Journal, 27, pp. 175-190. Available at: http://www.jstor.org/stable/23297062 (Accessed: 29 June 2017).

McGinnis, R. et al. (1973) 'The Limits to Growth: A Report for the Club of Rome's Project on the Predicament of Mankind.', Demography. Pan Books, 10(2), p. 295. doi: $10.2307 / 2060820$.

McGlade, C. and Ekins, P. (2015) 'The geographical distribution of fossil fuels unused when limiting global warming to $2{ }^{\circ} \mathrm{C}$, Nature, 517(7533), pp. 187-190. doi: 10.1038/nature14016.

Meadows, D. H. and Randers, J. (2013) Limits to Growth: The 30-Year Update. White River Junction, Vt: Chelsea Green Publishing Co. 
Miller, R. E. and Blair, P. D. (2009) Input-Analysis. Foundations and Extensions. Cambridge, UK: Cambridge University Press.

Mohr, S. H. et al. (2015) 'Projection of world fossil fuels by country', Fuel, 141, pp. 120135. doi: 10.1016/j.fuel.2014.10.030.

Moriarty, P. and Honnery, D. (2016) 'Can renewable energy power the future?', Energy Policy, 93, pp. 3-7.

Morita, T. et al. (2003) 'Long-term Scenarios based on AIM Model', in Climate Policy Assessment. Tokyo: Springer, pp. 17-36.

Nieto, J., Carpintero, Ó. and Miguel, L. J. (2018) 'Less than $2{ }^{\circ} \mathrm{C}$ ? An EconomicEnvironmental Evaluation of the Paris Agreement', Ecological Economics. doi: 10.1016/j.ecolecon.2017.10.007.

O’Neill, B. C. et al. (2017) 'The roads ahead: Narratives for shared socioeconomic pathways describing world futures in the 21 st century', Global Environmental Change, 42, pp. 169-180. doi: 10.1016/j.gloenvcha.2015.01.004.

Palmer, G. (2018) 'A Biophysical Perspective of IPCC Integrated Energy Modelling', Energies, 11(4), p. 839. doi: 10.3390/en11040839.

Pollit, H. (2014) 'Technical Manual, Version 6.0'. Cambridge Econometrics. Available at: https://www.camecon.com/wp-content/uploads/2016/09/E3ME-Manual.pdf.

Radzicki, M. J. (2009) 'System Dynamics and Its Contribution to Economics and Economic Modeling', in Complex Systems in Finance and Econometrics. New York, NY: Springer New York, pp. 727-737. doi: 10.1007/978-1-4419-7701-4_39.

Radzicki, M. J. and Tauheed, L. (2009) 'In Defense of System Dynamics: A Response to Professor Hayden', Journal of Economic Issues, 43(4), pp. 1043-1061. doi: 10.2753/JEI0021- 
3624430411.

Raftery, A. E. et al. (2017) 'Less than $2{ }^{\circ} \mathrm{C}$ warming by 2100 unlikely', Nature Climate Change, 7(9), pp. 637-641. doi: 10.1038/nclimate3352.

Raworth, K. (2018) Doughnut Economics: Seven Ways to Think Like a 21st-Century Economist. Random House Business.

Rezai, A. and Stagl, S. (2016) 'Ecological macroeconomics: introduction and review.', Ecological Economics, 121, pp. 181-185.

Režný, L. and Bureš, V. (2018) ‘Adding Feedbacks and Non-Linearity to the Neoclassical Growth Model: A New Realm for System Dynamics Applications', Systems, 6(2), p. 8. doi: 10.3390/systems6020008.

Riahi, K. et al. (2017) 'The Shared Socioeconomic Pathways and their energy, land use, and greenhouse gas emissions implications: An overview', Global Environmental Change. Pergamon, 42, pp. 153-168. doi: 10.1016/J.GLOENVCHA.2016.05.009.

Rogelj, J. et al. (2016) 'Paris Agreement climate proposals need a boost to keep warming well below $2{ }^{\circ} \mathrm{C}^{\prime}$, Nature, 534(7609), pp. 631-639. doi: 10.1038/nature18307.

Scrieciu, S., Rezai, A. and Mechler, R. (2013) 'On the economic foundations of green growth discourses: the case of climate change mitigation and macroeconomic dynamics in economic modeling', WENE, 2(3), pp. 251-268. doi: 10.1002/wene.57.

Sers, M. R. and Victor, P. A. (2018) 'The Energy-emissions Trap', Ecological Economics. Elsevier, 151, pp. 10-21. doi: 10.1016/J.ECOLECON.2018.04.004.

Sgouridis, S., Csala, D. and Bardi, U. (2016) 'The sower's way: quantifying the narrowing net-energy pathways to a global energy transition', Environmental Research Letters. IOP Publishing, 11(9), p. 094009. doi: 10.1088/1748-9326/11/9/094009. 
Spash, C. L. (2016) 'The political economy of Paris Agreement on human induced climathe change: a brief guide.', Real-World Economics Review, 75, pp. 67-75. Available at: http://www.paecon.net/PAEReview/issue75/Spash75.pdf.

Stehfest, E. et al. (2014) Integrated assessment of global environmental change with IMAGE 3.0: Model description and policy applications. Netherlands Environmental Assessment Agency (PBL).

Sterman, J. (2000) Business dynamics: systems thinking and modeling for a complex world. Irwin/McGraw-Hill.

Sterman, J. et al. (2012) 'Climate interactive: the C-ROADS climate policy model', System Dynamics Review. John Wiley \& Sons, Ltd, 28(3), pp. 295-305. doi: 10.1002/sdr.1474.

Stern, D. I. (1997) 'Limits to substitution and irreversibility in production and consumption: A neoclassical interpretation of ecological economics', Ecological Economics, 21(3), pp. 197-215. doi: 10.1016/S0921-8009(96)00103-6.

Stern, D. I. (2011) 'The Role of Energy in Economic Growth',. doi: 10.2139/SSRN.1878863.

Stockhammer, E., Onaran, Ö. and Ederer, S. (2009) 'Functional income distribution and aggregate demand in the Euro area', Cambridge J Econ, 33(1), pp. 139-159. doi: 10.1093/cje/ben026.

Taylor, L., Rezai, A. and Foley, D. K. (2016) 'An integrated approach to climate change, income distribution, employment, and economic growth', Ecological Economics, 121, pp. 196205. doi: 10.1016/j.ecolecon.2015.05.015.

Timmer, M. et al. (2015) ‘An Illustrated User Guide to the World Input-Output Database: the Case of Global Automotive Production', Review of International Economics, 23(3), pp. 575605. 
http://econpapers.repec.org/article/blareviec/v_3a23_3ay_3a2015_3ai_3a3_3ap_3a575-605.htm (Accessed: 29 June 2017).

Uehara, T., Nagase, Y. and Wakeland, W. (2013) 'Integrating Economics and System Dynamics Approaches for Modeling an Ecological-Economic System', Systems Science Faculty Publications and Presentations. Available at: http://pdxscholar.library.pdx.edu/sysc_fac/63.

Victor, P. A. and Rosenbluth, G. (2007) 'Managing without growth', Ecological Economics, 61(2), pp. 492-504. doi: 10.1016/j.ecolecon.2006.03.022.

van Vuuren, D. P. et al. (2012) 'Scenarios in Global Environmental Assessments: Key characteristics and lessons for future use', Global Environmental Change. Pergamon, 22(4), pp. 884-895. doi: 10.1016/J.GLOENVCHA.2012.06.001.

Zittel, W. and Schindler, J. (2006) Uranium Resources and Nuclear Energy. Ottobrunn/Achen: Energy Watch Group. 


\section{Appendix A. List of industries}

\begin{tabular}{|c|c|c|c|}
\hline \multicolumn{4}{|c|}{ Sectors } \\
\hline 1 & $\begin{array}{l}\text { Agriculture, Hunting, Forestry and } \\
\text { Fishing }\end{array}$ & 18 & Construction \\
\hline 2 & Mining and Quarrying & 19 & $\begin{array}{l}\text { Sale, Maintenance and Repair of Motor } \\
\text { Vehicles and Motorcycles; Retail sail of fuel }\end{array}$ \\
\hline 3 & Food, Beverages and Tobacco & 20 & $\begin{array}{l}\text { Wholesale Trade and Commission Trade, } \\
\text { Except of Motor Vehicles and Motorcycles }\end{array}$ \\
\hline 4 & Textiles and Textile Products & 21 & $\begin{array}{l}\text { Retail Trade, Except of Motor Vehicles and } \\
\text { Motorcycles; Repair of Household goods }\end{array}$ \\
\hline 5 & Leather, Leather and Footwear & 22 & Hotels and Restaurants \\
\hline 6 & Wood and Products of Wood and Corks & 23 & Inland Transport \\
\hline 7 & Pulp, Paper, Printing and Publishing & 24 & Water Transport \\
\hline 8 & Coke, Refined Petroleum and Nuclear fuel & 25 & Air Transport \\
\hline 9 & Chemicals and Chemical Products & 26 & $\begin{array}{l}\text { Other Supporting and Auxiliary Transport } \\
\text { Activities; Activities of Travel Agencies }\end{array}$ \\
\hline 10 & Rubber and Plastics & 27 & Post and Telecommunications \\
\hline 11 & Other Non-Metallic Mineral & 28 & Financial Intermediation \\
\hline 12 & Basic Metals and Fabricated Metal & 29 & Real Estate Activities \\
\hline 13 & Machinery, Nec & 30 & $\begin{array}{l}\text { Renting of M\&Eq and Other Business } \\
\text { Activities }\end{array}$ \\
\hline 14 & Electrical and Optical Equipment & 31 & $\begin{array}{l}\text { Public Admin and Defence; Compulsory } \\
\text { Social Security }\end{array}$ \\
\hline 15 & Transport Equipment & 32 & Education \\
\hline 16 & Manufacturing, Nec.; Recycling & 33 & Health and Social Work \\
\hline 17 & Electricity, Gas and Water supply & 34 & $\begin{array}{l}\text { Other Community, Social and Personal } \\
\text { Services }\end{array}$ \\
\hline & & 35 & Private Households with Employed Persons \\
\hline
\end{tabular}

Source: Own compilation on the basis of WIOD (Dietzenbacher et al., 2013) 


\section{Appendix B. Target matrices for the World model.}

BAU- Gradually evolving from 2020 to 2050 at historical rates, limited to maintain the consistency of accounting balances. The historical average growth rate of every component of the A matrix is estimated, i.e. 1225 rates. Then every A matrix component $a_{i j}$ is projected applying its average growth rate. This can lead to inconsistencies that have been avoided:

Total intermediate inputs proportion being higher than 1 or lower than zero. For this purpose, 1 and 0 were set as maximum and minimum for this proportion respectively.

Total intermediate inputs proportion being high or low enough to reduce or increase gross value added in an unrealistic way. Gross value added proportion over sectoral output can only be $1 / 3$ higher or lower than its initial value.

For instance, sector 2 has an intermediate inputs' share of 0.318 as its last observed value and starts declining after 2020. It only decreases 0.275 by 2050 with a gross value added share 0.725 . Otherwise it could have led to gross value added being $95 \%$ of total output or even lower than zero. Nevertheless, the most common situation is technical coefficients going higher and therefore, reducing the economy's capability to create gross value added out of production. This system allows the BAU scenario continue its current trajectory avoiding gross value added to shrink.

Green growth- Denmark A Matrix (last observation). The Denmark's IOT was transformed into a one-region matrix, incorporating intermediate inputs from imports to the purchases made by Denmark's sectors domestically. Additionally, exports have been considered as domestic sales. This way, we can evaluate the economic performance of the global economy (where imports are equal to exports) if its sectoral trade flows had the same structure as Denmark, one of the most important countries in terms of domestic sustainability, and a European, modern and efficient country.

Post-growth- Ad-hoc matrix fostering less energy-intensive sectors and improving the efficiency of the energy producing sector. Method: increasing sales weights (row coefficients) and reducing purchases weights (column coefficients), respectively, by a factor (see Figure A.3). By affecting the technical coefficients by rows, the implicit assumption is that every sector will purchase more (or less) intermediate products or services from the sector that is being modified. For instance, if we want to evaluate in this scenario a situation whereby all the economy is going to transit to electrification, is to be expected that all industries will increase their purchases from sector 17 (see Appendix A). This would imply that the proportion in which sectors will use 
products from sector 17 over their total output will be higher. As a consequence, row 17 of the technical coefficients matrix is multiplied by 1.40 factor. Analogously, by predicting a less material-intensive future within the Post-Growth scenario, a $10 \%$ reduction in intermediate consumption is operated by multiplying by a 0.90 factor by columns. These row and column factors can be seen broken down by sectors below the target matrix. 
BAU final A matrix (World level) and different year's sum of columns (share of intermediate products on total output)

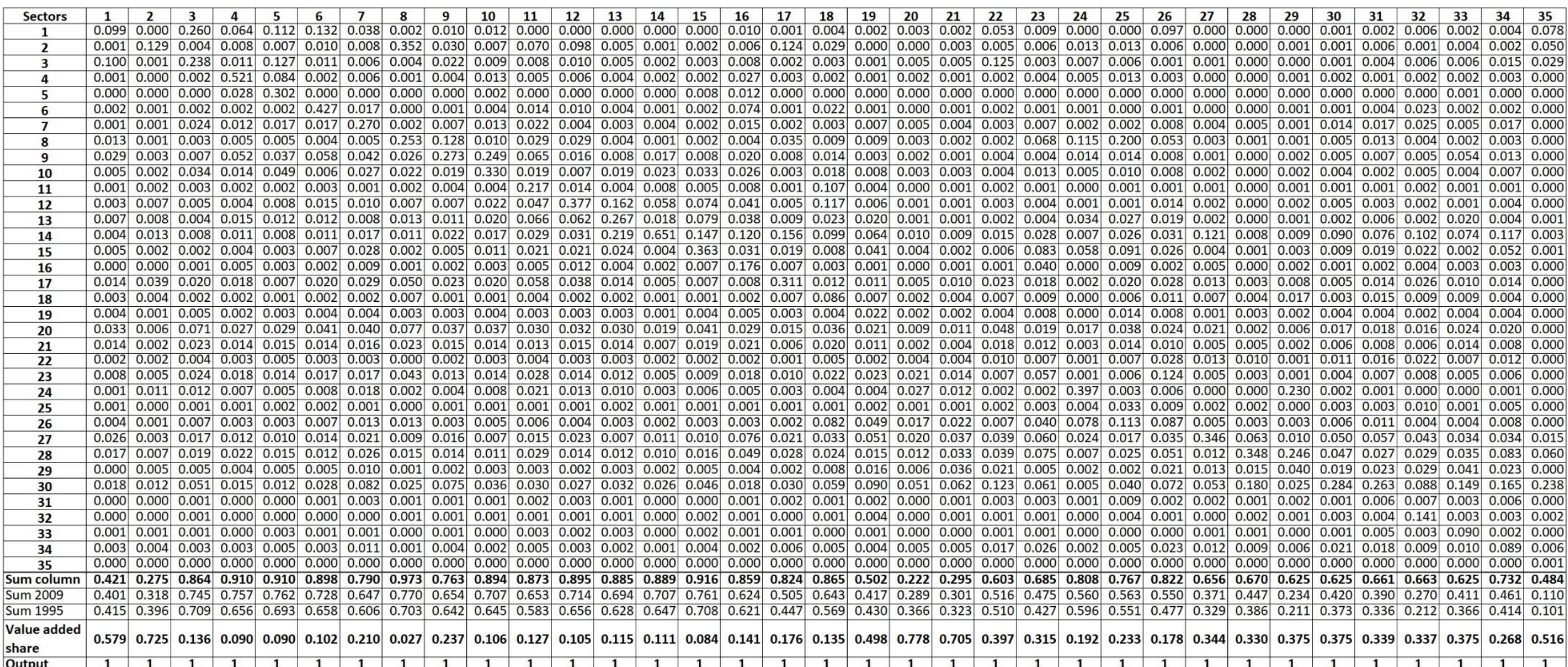

Own elaboration. 
Green growth scenario target A matrix (World level)

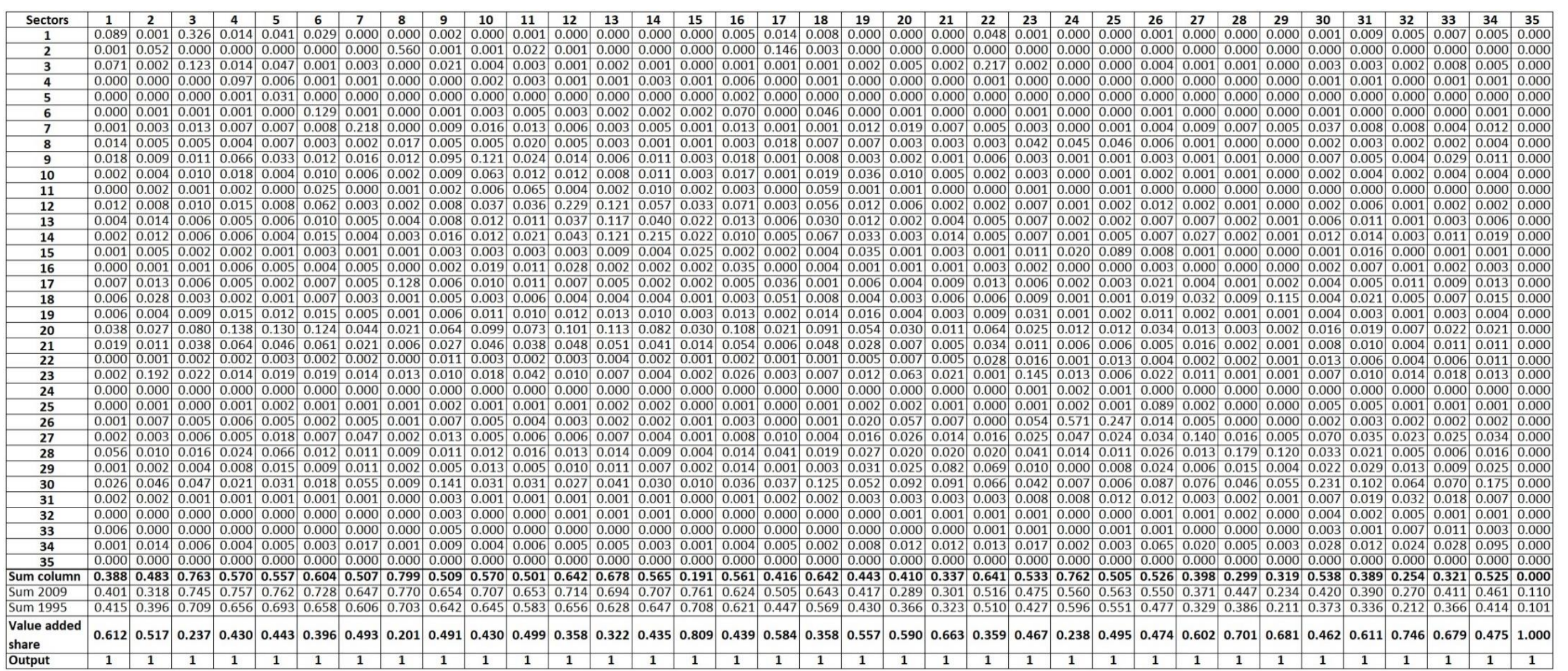

Own elaboration from WIOD (Dietzenbacher et al., 2013) 
Post growth scenario A matrix (World level)

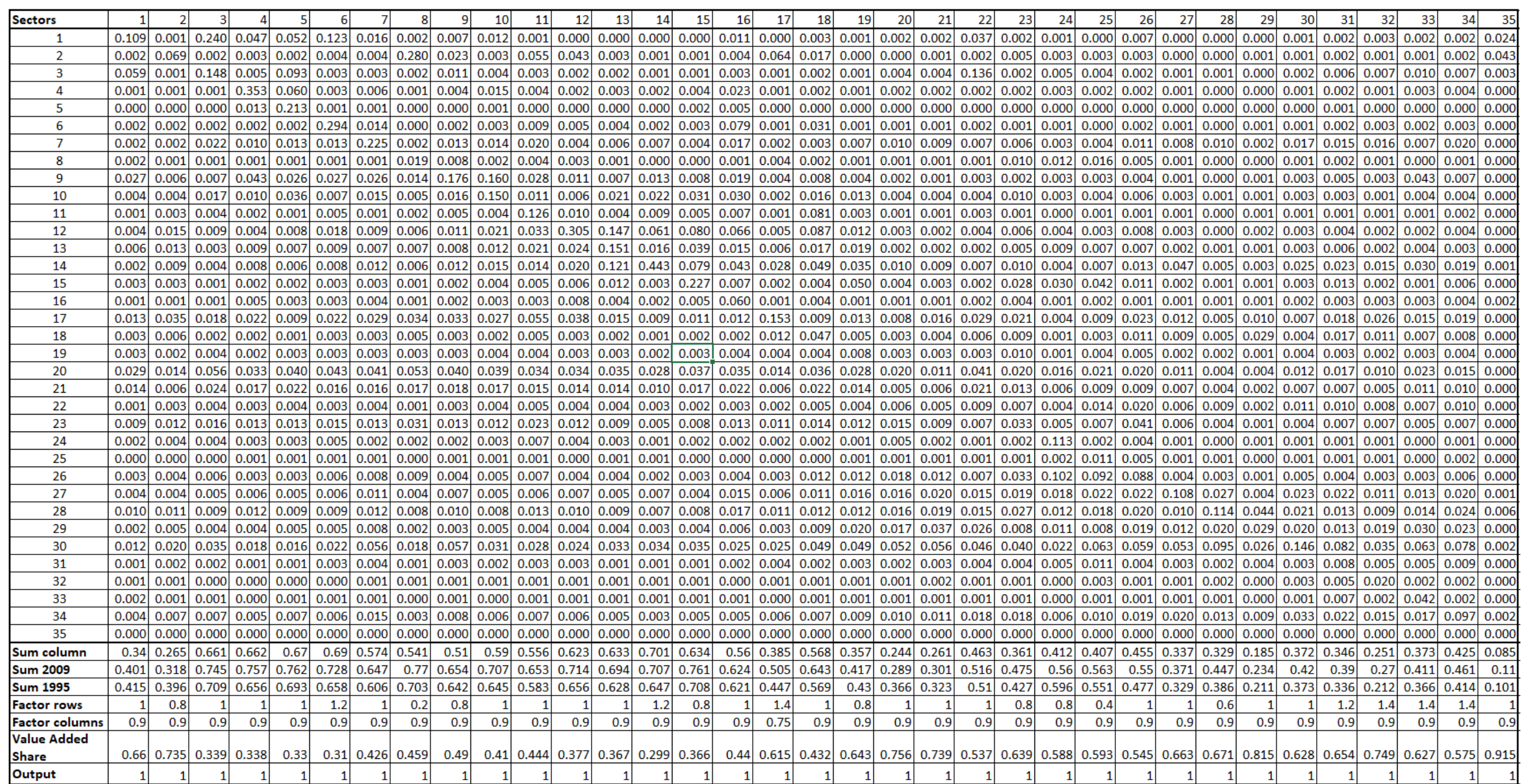

Own elaboration 


\section{Appendix C. Direct and indirect effects}

Input-Output Analysis (IOA) allows the sectoral production required to satisfy an exogenous variation in demand to be calculated. As we already know, IOA encompasses the set of inputs that each industry needs from the others in order to produce its output (technical coefficients). Thus, by means of this structure, the variation in final demand not only triggers a direct reaction in economic output, but also an indirect one, regarding the cross-industry demand for intermediate products. Hence, IOA lets us separate the total effects of a variation in final demand between direct effects and indirect effects on production. As the total production (on the demand side) equals the row sum of sectoral intermediate consumption, plus sectoral final demand, both figures would represent indirect and direct effects, respectively. Moreover, by using energy coefficients (i.e., energy intensities), we can obtain energy carriers from each effect. Since MEDEAS-World takes household energy consumption separately (Eq.10), additional arrangements must be made to correctly track the energy carriers of direct effects. Therefore, considering that $\mathrm{fd}=\mathrm{x}-\mathrm{Z}$, the indirect and direct energy carrier effects are calculated as follows:

$$
\mathbf{D E}^{\mathbf{k i}}=\hat{\mathbf{e}}^{\mathbf{k i}} \cdot\left(\mathbf{x}^{\prime}-\mathbf{r}^{\prime}\right)+\widehat{\mathbf{h h}_{-}} \mathbf{e}^{\mathbf{k i}} \cdot \mathbf{c} \quad \text { Eq. C. } 1
$$

$$
\mathbf{I} \mathbf{E}^{\mathbf{k i}}=\hat{\mathbf{e}}^{\mathbf{k i}} \cdot \mathbf{r}^{\prime}
$$

where $\mathbf{D E}^{\mathbf{k i}}$ and $\mathbf{I E}^{\mathbf{k i}}$ are both direct and indirect energy carrier effects, $\mathbf{r}^{\prime}$ is the row vector of the row's sum of intermediate consumption by industry ' $i$ ' $\left(\sum_{j=1}^{35} z_{i j}\right)$, $\hat{\mathbf{e}}^{\mathbf{k i}}$ is the energy intensities by sector and $\widehat{\mathbf{h h} \_} \mathbf{e}^{\mathbf{k i}}$ household energy intensity (both intensities' diagonal matrices equal to those in section 3.1.4 since sectors ' $\mathrm{i}$ '=sectors ' $\mathrm{j}$ '), $\mathbf{c}$ stands for the households' demand for industry i's products and $\mathbf{x}^{\prime}$ the row vector of economic output. In order to check the validity of Eqs. A.1 and A.2, let us define the total effects (TE ${ }^{\mathrm{ki}}$ ) as the sum of both:

$$
\mathbf{T E}^{\mathbf{k i}}=\hat{\mathbf{e}}^{\mathbf{k i}} \cdot\left(\mathbf{x}^{\prime}-\mathbf{r}^{\prime}\right)+\widehat{\mathbf{h h}}_{\mathbf{e}}^{\mathbf{k i}} \cdot \mathbf{c}+\hat{\mathbf{e}}^{\mathbf{k i}} \cdot \mathbf{r}^{\prime} \quad \text { Eq. C.3 }
$$

and then, operating:

$$
\mathbf{T E}^{\mathbf{k i}}=\hat{\mathbf{e}}^{\mathbf{k i}} \cdot\left(\mathbf{x}^{\prime}-\mathbf{r}^{\prime}+\boldsymbol{r}^{\prime}\right)+\widehat{h}_{\mathbf{h}}^{\mathbf{e}}{ }^{\mathbf{k i}} \cdot \mathbf{c}=\hat{\mathbf{e}}^{\mathbf{k i}} \cdot\left(\mathbf{x}^{\prime}\right)+\widehat{\mathbf{h h}} \_^{\mathbf{k i}} \cdot \mathbf{c} \quad \text { Eq. A.4 }
$$

which, considering that $\mathbf{x}$ ' $=\mathbf{x}$ and sectors ' $\mathrm{i}$ ' and ' $\mathrm{j}$ ' are equal but by rows and columns respectively, exactly equals Eq.10 


\section{Appendix D. World Economy module views}

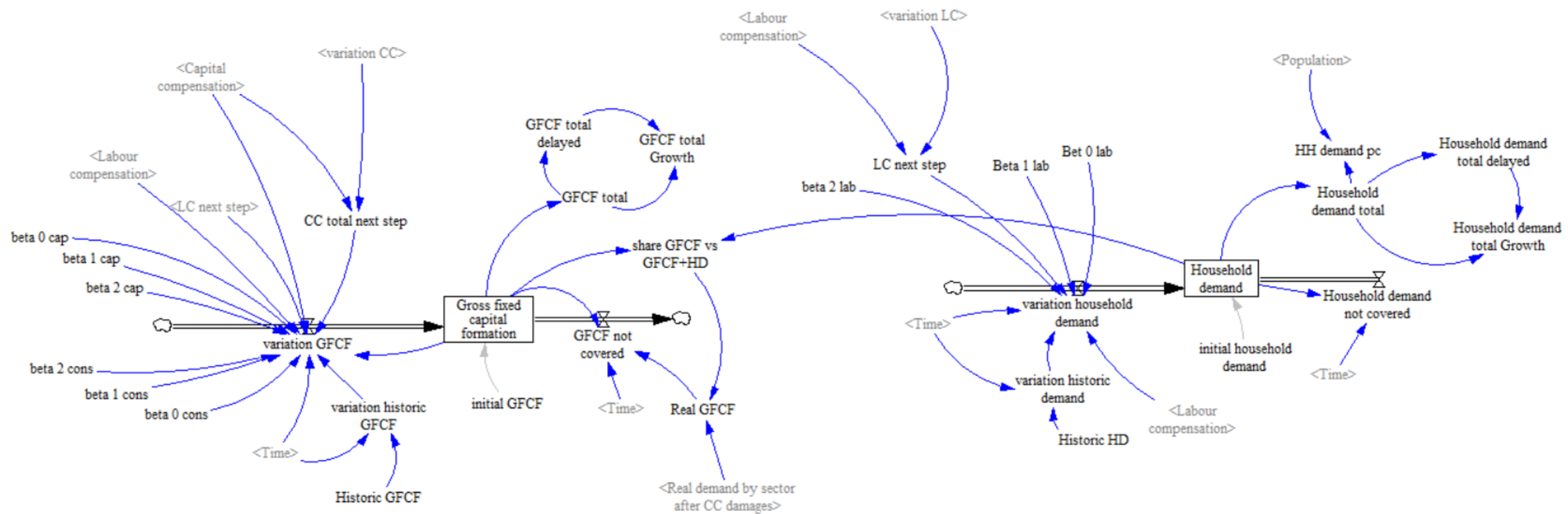

'DEM-ECON. Investment and Households' View in MEDEAS-World. 


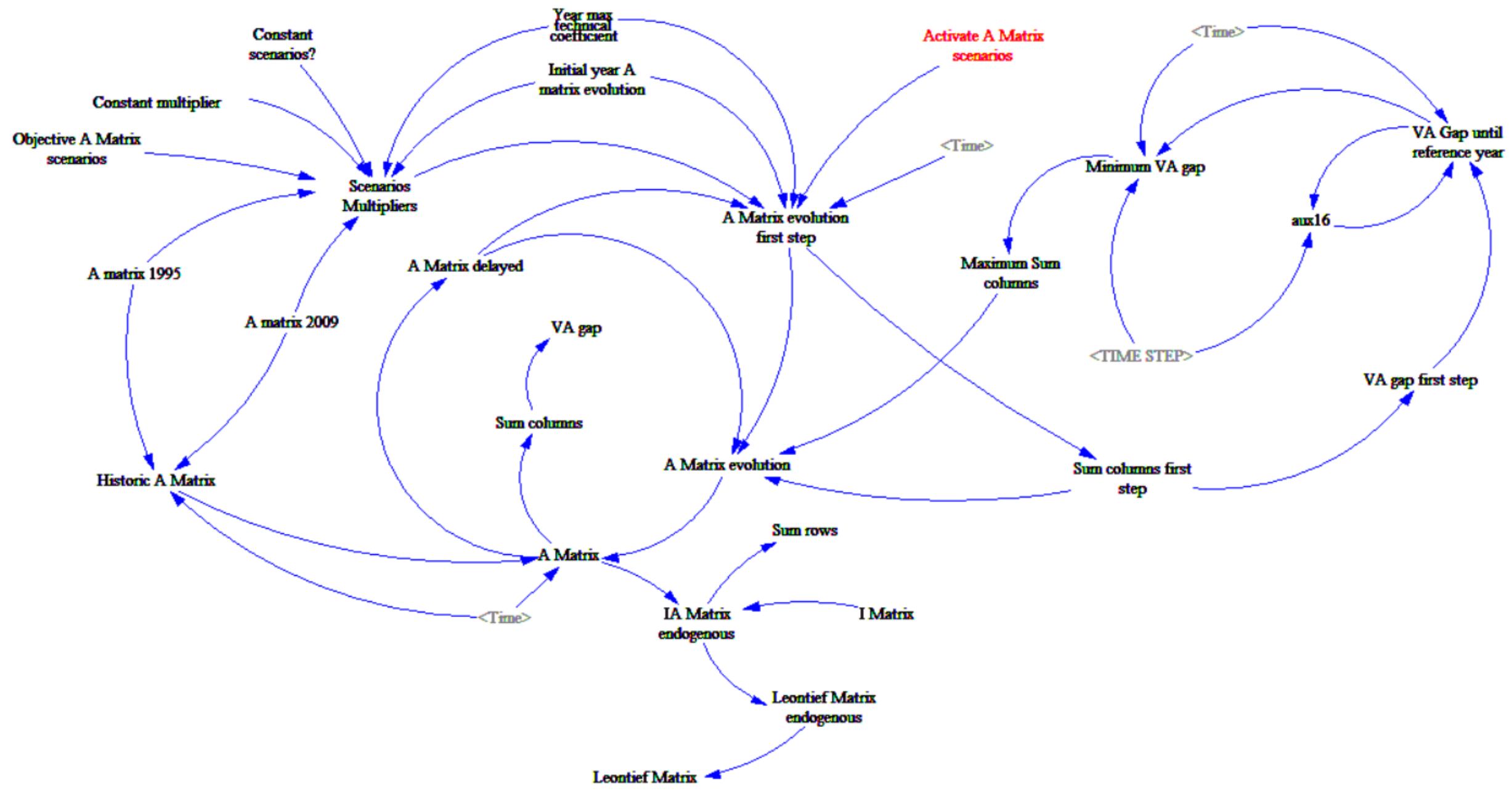

'ECON. Economic structure - A matrix evolution' view in MEDEAS-World. 


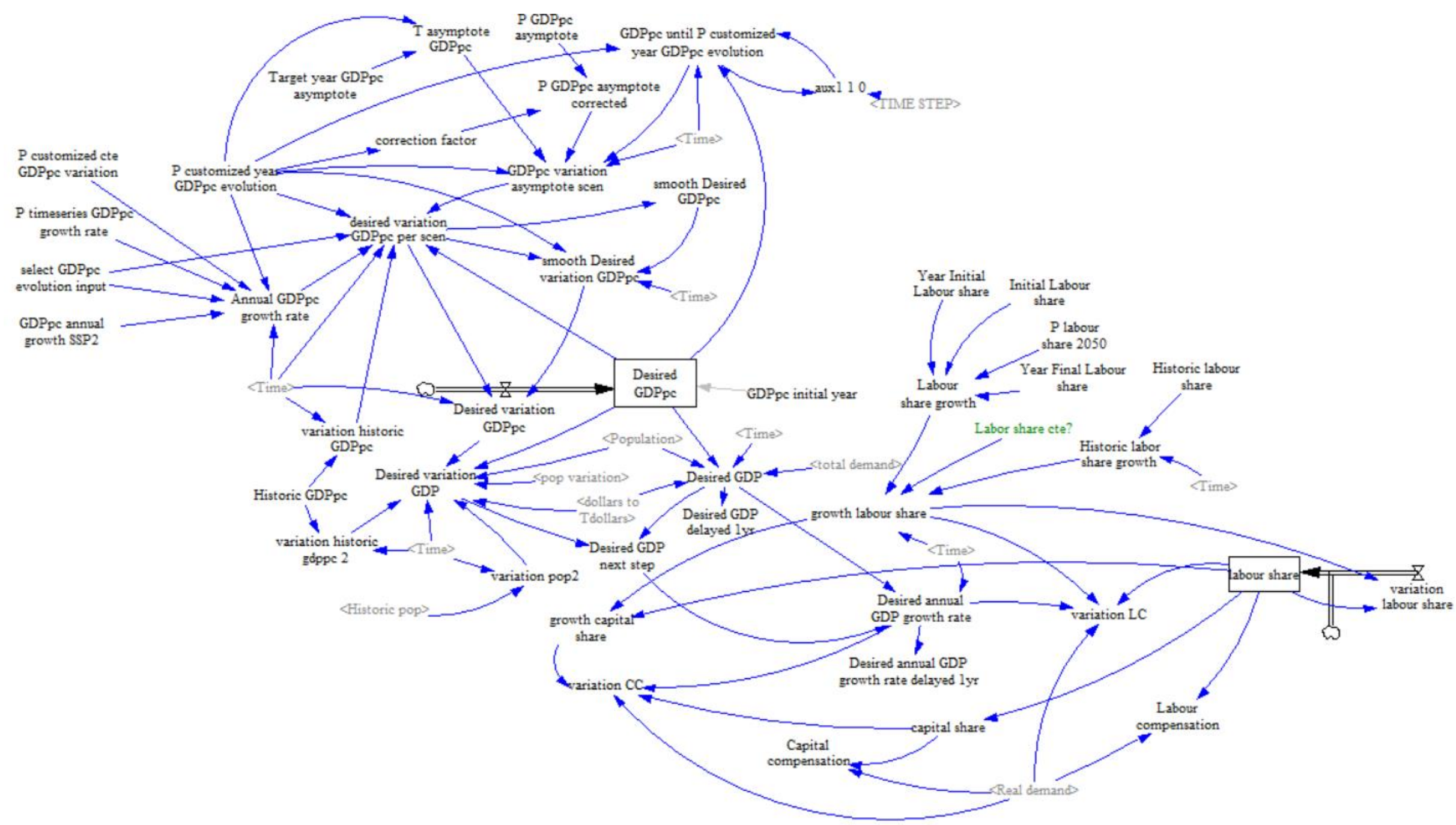

'DEM ECON - Income. Labour and capital compensation' view in MEDEAS-World. 


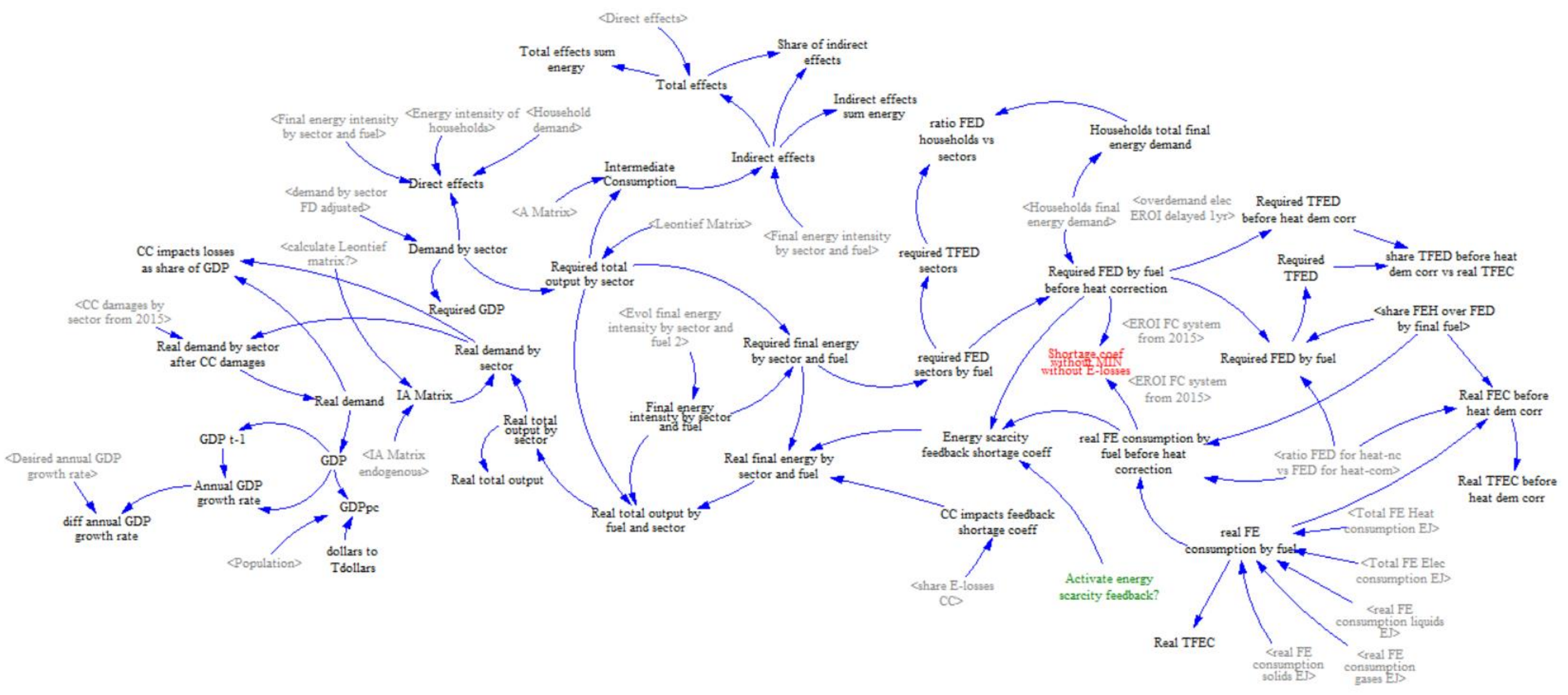

'ECON. Confrontation demand with limits' view in MEDEAS-World. 